\title{
LEY CHILENA CONTRA LA DISCRIMINACIÓN. UNA EVALUACIÓN DESDE LOS DERECHOS INTERNACIONAL Y CONSTITUCIONAL*
}

\author{
CHILEAN LAW AGAINST DISCRIMINATION. \\ AN EVALUATION FROM INTERNATIONAL AND CONSTITUTIONAL \\ $L A W$
}

\begin{abstract}
Iván Dí́az García ${ }^{*}$
RESUMEN: El artículo confronta la concepción de discriminación contenida en la ley 20.609 con la que se expresa en el Derecho internacional de los derechos humanos y en el Derecho constitucional chileno. En particular se contrastan tres elementos constitutivos de aquella concepción: el concepto de discriminación, la función de las categorías sospechosas en la identificación de una conducta discriminatoria y la solución de las colisiones entre la no discriminación y otros derechos fundamentales o bienes jurídicos constitucionales. Este contraste permite formarse una opinión negativa respecto de la utilidad de la acción procesal incluida en aquella ley.
\end{abstract}

Palabras clave: Discriminación, Ley 20.609, Derecho constitucional, Derecho internacional, Derechos humanos.

ABSTRACT: The paper confronts the way discrimination is understood in law number 20.609 with the way it is understood in Human Rights International Law and in the Chilean Constitutional Law. Particularly, three constitutive elements of this understanding are compared: the concept of discrimination, the role that suspicious categories have in identifying a discriminatory conduct and the solutions given to the collision among non-discrimination and other fundamental rights or constitutional protected legal rights. This confrontation allows to form a negative opinion about the usefulness of the court action included in the mentioned law.

Key words: Discrimination, 20.609 Act., Constitutional law, International law, Human rights.

\section{INTRODUCCIÓN}

La no discriminación es uno de los principios fundamentales del Derecho internacional de los derechos humanos, según lo muestra su consagración en diversos instrumentos

\footnotetext{
* Agradezco sinceramente los aportes a una versión preliminar de esta investigación formulados por los académicos Alejandra Cid, Juan Pablo Beca, Eduardo Castillo, Juan Jorge Faundes, Alberto Olivares y Herman Saavedra, los que sin duda permitieron mejorar el trabajo. Las omisiones y fallos que subsisten son, evidentemente, de exclusiva responsabilidad del autor.

** Académico en la Facultad de Ciencias Jurídicas de la Universidad Católica de Temuco (Chile). Abogado Pontificia Universidad Católica de Chile. Doctor en Derecho Universidad Carlos III de Madrid. Manuel Montt 056,Temuco. Ivandiaz@uct.cl. (56) (45) 205326.
} 
internacionales tanto universales ${ }^{1}$ como regionales $^{2}$. Además, y en su calidad de valor jurídico constitucional fundamental, enraíza profundamente en la noción de dignidad de la persona. Por ello no es de extrañar que se contemple estrechamente vinculada con aquella tras la expresión igualdad en la Constitución chilena ${ }^{3}$. De este modo, y en cuanto garantía de una vida digna y estándar de legitimidad del poder político, el disfrute del derecho a la no discriminación debe ser efectivamente resguardado por el ordenamiento jurídico nacional.

Desde tales coordenadas, se debe recordar que el 24 de julio del año 2012 se publicó en el Diario Oficial la ley 20.609, que establece medidas en contra de la discriminación. Más allá del entusiasmo político y social que ha despertado esta iniciativa legal, se trata de un texto normativo que ha sido objeto de importantes objeciones desde el mundo jurídico. En efecto, la Corte Suprema se pronunció negativamente en dos de las oportunidades en que se le solicitó su opinión respecto de la utilidad del proyecto de ley que dio lugar a la ley mencionada. Considerando que la Constitución asegura a todas las personas la igualdad ante la ley y prohíbe toda discriminación arbitraria, y que contempla la acción de protección en su artículo 20, sostuvo que el derecho a la no discriminación se encontraba suficientemente tutelado, por lo que esta ley era innecesaria ${ }^{4}$. En similar sentido, se han pronunciado académicos universitarios ${ }^{5}$.

Ahora bien, el presente trabajo no pretende clarificar si la ley 20.609 constituye una herramienta útil o necesaria en el marco del ordenamiento jurídico chileno en el ámbito de la discriminación, al menos no directamente. Su objetivo es evaluar la coherencia de la concepción de discriminación contenida en la ley respecto de la prevaleciente en el Derecho internacional de los derechos humanos y el Derecho constitucional, y los impactos que

\footnotetext{
1 Artículo 2 de la Declaración Universal de Derechos Humanos, artículo 2 del Pacto Internacional de Derechos Civiles y Políticos (en adelante el Pacto), artículo 1 de la Convención Internacional sobre la eliminación de todas las formas de discriminación racial, artículo 1 de la Convención sobre la eliminación de todas las formas de discriminación contra la mujer, artículo 2 de la Convención de los derechos del niño y artículo 2 de la Convención sobre los derechos de las personas con discapacidad.

2 Artículo II de la Declaración Americana de los derechos y deberes del hombre y artículos 1 y 24 de la Convención Americana sobre Derechos Humanos (en adelante la Convención Americana).

3 El artículo $1^{\circ}$, inciso primero, de la Constitución Política de la República de Chile (1980) (en adelante la Constitución chilena) dispone, en lo que aquí interesa, que las personas nacen iguales en dignidad.

4 Textualmente sostuvo la Corte Suprema: “este tribunal es de opinión que el derecho a la no discriminación está suficientemente abordado, regulado y cautelado en el ordenamiento jurídico vigente, por lo que no se aprecia la necesidad de establecer acciones adicionales y especiales para su resguardo". Corte Suprema (2005a). La opinión se reitera textualmente, aunque con nuevos reparos a las modificaciones experimentadas por el proyecto durante su tramitación, en Corte Suprema (2005b). Pese a que se mantiene el carácter innecesario de la iniciativa, la Corte Suprema decide pronunciarse favorablemente en los siguientes dos Oficios relativos a este proyecto de ley y desfavorablemente en el último de ellos. Ver Corte Suprema (2007), Corte Suprema (2008) y Corte Suprema (2011).

5 Aunque la opinión crítica de varios académicos se presentará a lo largo de este trabajo, merece la pena destacar en este momento las opiniones de Llanquilef (2012) y de Corral (2012) respecto de la utilidad de la ley. El primero expresó categóricamente que el entonces proyecto de ley prácticamente no establecía medidas o herramientas novedosas a partir de la arista jurídica. Según Hernán Corral, por su parte, para impedir, sancionar y reparar los actos discriminatorios basta el ordenamiento jurídico vigente y no es necesaria una legislación especial, por lo que, a su juicio, la pertinacia con la que se persigue su aprobación tiene un objetivo cultural, político e ideológico que va mucho más allá que la de evitar las discriminaciones injustificadas.
} 
aquella concepción genera, como consecuencia, en la utilidad que pueda tener la acción procesal contra la discriminación contemplada en la misma ley. Estos deslindes implican excluir otros aspectos regulados por la ley, y singularmente el mandato a los órganos del Estado para que aseguren la no discriminación, la agravante de responsabilidad penal relativa a que el delito se cometa por razones discriminatorias, y la configuración o características de la acción procesal establecida.

En este sentido, las preguntas que orientan la presente investigación son dos y pueden ser formuladas de la siguiente manera: jes coherente la concepción de discriminación contenida en la ley 20.609 con la concepción de discriminación sostenida por el Derecho internacional de los derechos humanos y por el Derecho constitucional chileno? ¿Qué consecuencias acarrea la respuesta a la pregunta anterior en la utilidad que presenta la acción procesal establecida en la propia ley? Como se podrá suponer, la respuesta a estas preguntas permitirá clarificar, indirectamente, si dicha ley, y singularmente su acción procesal, es útil o necesaria.

Con la finalidad de responder a las mencionadas preguntas el discurso se vertebra en torno a tres apartados. En el primero de ellos se contrastan los requisitos del concepto de discriminación establecidos por los Derechos internacional y constitucional con los establecidos por la ley 20.609. En el segundo se analiza el rol que juegan las denominadas categorías sospechosas en los Derechos internacional y constitucional frente al papel que asumen en la ley en comento. En el último se evalúa la solución a las colisiones entre el derecho a la no discriminación y otros derechos o bienes jurídicos que establecen el Derecho internacional, el Derecho constitucional y la mencionada ley. El conjunto conformado por estas tres variables (concepto de discriminación, incidencia de las categorías sospechosas y solución de colisiones entre discriminación y otros derechos) constituye lo que aquí se ha denominado concepción de discriminación.

\section{EL PROBLEMA DE LOS REQUISITOS DEL CONCEPTO DE DISCRIMINACIÓN}

\section{Requisitos del concepto de discriminación en el Derecho INTERNACIONAL}

En cuanto al concepto de discriminación en el Derecho internacional, el Comité de Derechos Humanos de Naciones Unidas ha expresado que no toda diferenciación de trato constituirá una discriminación, si los criterios para tal diferenciación son razonables y objetivos y lo que se persigue es lograr un propósito legítimo en virtud del Pacto Internacional de Derechos Civiles y Políticos (en adelante el Pacto) ${ }^{6}$. De este modo, resulta posible entender que se está frente a una discriminación si se produce una diferencia de trato que no es razonable ni objetiva, ni se persigue un fin legítimo en virtud de dicho Pacto.

Similar es la posición de la Corte Interamericana de Derechos Humanos. Siguiendo la jurisprudencia del Tribunal Europeo de Derechos Humanos, ha explicado que "solo es

6 Comité de Derechos Humanos de Naciones Unidas (1989) párrafo 13. 
discriminatoria una distinción cuando carece de justificación objetiva y razonable" ${ }^{7}$. Profundizando aquella noción, sostuvo que no existirá discriminación "si una distinción de tratamiento está orientada legítimamente, es decir, si no conduce a situaciones contrarias a la justicia, a la razón o a la naturaleza de las cosas"8.

Por último, y por razones que se explicitarán más abajo, conviene destacar la relación entre discriminación y derechos estatuidos por el Derecho internacional. En el ámbito universal, el Comité de Derechos Económicos, Sociales y Culturales de Naciones Unidas ha observado que, en virtud de lo dispuesto en el Pacto, el derecho a la no discriminación debe ser en sí mismo protegido mediante un recurso judicial efectivo, sin necesidad de referencia a otros derechos ${ }^{9}$. En el mismo sentido, el Comité de Derechos Humanos, interpretando el significado del principio de no discriminación en el mencionado Pacto, ha explicado que sus artículos 2 y 26 establecen derechos autónomos ${ }^{10}$. El artículo 2 protege contra discriminaciones en el disfrute de los derechos estatuidos en ese instrumento ${ }^{11}$. Por el contrario, el artículo 26 prohíbe la discriminación de hecho o de Derecho en cualquier esfera, de modo que no se limita al ámbito de los derechos enunciados en el mismo ${ }^{12}$. Esto significa que, de acuerdo con la doctrina del Comité de Derechos Humanos, se puede estar frente a una discriminación aun cuando no se afecten los derechos estatuidos en el Pacto.

La misma perspectiva tiene la Corte Interamericana respecto de la relación entre discriminación y derechos estatuidos en el ámbito de la Convención Americana de Derechos Humanos (en adelante la Convención Americana). Sobre el punto ha sostenido que si un Estado discrimina en el respeto o garantía de un derecho convencional, violaría el artículo 1.1 y el derecho sustantivo en cuestión. Si por el contrario la discriminación se refiere a una protección desigual de la ley interna, violaría el artículo 24 de dicha Convención ${ }^{13}$.

\footnotetext{
7 Corte Interamericana de Derechos Humanos (1984) párrafo 56.

8 Corte Interamericana de Derechos Humanos (2003) párrafo 91.

9 Al respecto expresó el Comité de Derechos Económicos, Sociales y Culturales: "De hecho, los Estados Partes que son asimismo Partes en el Pacto están ya obligados (en virtud de los artículos 2 (párrs. 1 y 3 ), 3 y 26 de este Pacto) a garantizar que toda persona cuyos derechos o libertades (inclusive el derecho a la igualdad y a la no discriminación) reconocidos en el presente Pacto hayan sido violados, "podrá interponer un recurso efectivo" (apartado a) del párrafo 3 del artículo 2)”. Ver Comité de Derechos Económicos, Sociales y Culturales de Naciones Unidas (1990) párrafo 5.

10 Comité de Derechos Humanos de Naciones Unidas (1989) párrafo 12.

11 A partir de lo estatuido en el artículo 2 y considerando lo prescrito en otros instrumentos internacionales, el Comité de Derechos Humanos de Naciones Unidas ha sostenido que la discriminación consiste en "toda distinción, exclusión, restricción o preferencia que se basen en determinados motivos, como la raza, el color, el sexo, el idioma, la religión, la opinión política o de otra índole, el origen nacional o social, la posición económica, el nacimiento o cualquier otra condición social, y que tengan por objeto o por resultado anular o menoscabar el reconocimiento, goce o ejercicio, en condiciones de igualdad, de los derechos humanos y libertades fundamentales de todas las personas". Ver Comité de Derechos Humanos de Naciones Unidas (1989) párrafo 7.

12 En este mismo sentido, el Comité de Derechos Humanos de Naciones Unidas sostuvo que "la prohibición de la discriminación que prevé el artículo 26 no comprende tan solo los derechos garantizados en el Pacto". Ver Järvinen c. Finlandia (1990) párrafo 6.2. La misma doctrina se encuentra en Comité de Derechos Humanos de Naciones Unidas (1989) párrafo 12.

13 Corte Interamericana de Derechos Humanos (2010) párrafo 272. En el mismo sentido, Corte Interamericana de Derechos Humanos (2012) párrafo 82.
} 
En suma, las interpretaciones del Comité de Derechos Económicos, Sociales y Culturales, del Comité de Derechos Humanos y de la Corte Interamericana son coincidentes. Los dos últimos entienden que se está frente a una discriminación si se cumplen dos requisitos: que exista una diferencia de trato y que esa diferencia carezca de lo que aquí se denominará justificación admisible ${ }^{14}$. Adicionalmente, los dos Comités expresamente han independizado la noción de discriminación de la lesión de derechos contemplados en el Derecho internacional.

\section{Los Requisitos del concepto de discriminación en el Derecho CONSTITUCIONAL}

En la Constitución chilena hay referencias tanto explícitas como implícitas a la discriminación. En forma explícita la expresión se utiliza en tres oportunidades en el texto constitucional. Bajo forma de prohibición, se dirige a los particulares en el ámbito laboral ${ }^{15}$, al Estado y sus organismos en materia económica ${ }^{16}$, y de modo específico a los acuerdos que adopte el Banco Central ${ }^{17}$. La expresión discriminar aparece implícita en la Constitución, como prohibición esencialmente adscrita al artículo 19, número 2, que establece la igualdad ante la ley. Así lo ha sentenciado reiteradamente el Tribunal Constitucional chileno ${ }^{18}$,

14 En este trabajo se ha optado por la expresión “justificación admisible” entendiendo que se cumple si se reúnen dos requisitos. En primer lugar, que se cuente con una justificación, es decir, con una o más razones que argumenten a favor de una determinada proposición. En segundo lugar, que esa justificación sea admisible, es decir, que pueda ser considerada aceptable o suficiente por el auditorio al que va dirigida la justificación. En este sentido, se hace sinónimo de la expresión "razón suficiente" utilizada por Alexy al momento de exigir un grado de fundamentación para el tratamiento diferente. Por cierto la expresión "justificación admisible" (al igual que "razón suficiente") alude a la calidad de la fundamentación de un discurso jurídico. Y la calidad de un discurso jurídico está determinada por los contextos en que el mismo se expresa. En este sentido explica Alexy: "Los discursos jurídicos, aun cuando sean racionales, no conducen siempre a un mismo resultado y aun cuando en un determinado momento conduzcan a un mismo resultado, este puede ser diferente en otro momento". Ver Alexy (2001) nt. 39 p. 396 y p. 397.

15 Dispone el artículo 19, número 16, inciso tercero, de la Constitución chilena: "Se prohíbe cualquiera discriminación que no se base en la capacidad o idoneidad personal, sin perjuicio de que la ley pueda exigir la nacionalidad chilena o límites de edad para determinados casos".

16 El artículo 19, número 22, de la Constitución chilena, expresa: "La Constitución asegura a todas las personas la no discriminación arbitraria en el trato que deben dar el Estado y sus organismos en materia económica”.

17 El inciso cuarto del artículo 109 de la Constitución chilena prescribe lo siguiente: "El Banco Central no podrá adoptar ningún acuerdo que signifique de una manera directa o indirecta establecer normas o requisitos diferentes o discriminatorios en relación a personas, instituciones o entidades que realicen operaciones de la misma naturaleza”.

18 En este sentido resulta posible citar diversas sentencias. Así, el Tribunal Constitucional chileno ha sentenciado en la causa rol 2152-2011-CPR, de 19 de enero de 2012, considerando trigésimo sexto, que la disposición que establece en forma discriminatoria un acceso privilegiado a la información contenida en el Registro Electoral solo en favor de centros de estudios o de investigación contraviene el principio de igualdad ante la ley del artículo 19, número 2, de la Constitución (ver Proyecto de ley sobre inscripción automática, Servicio Electoral y sistema de votaciones, rol 2152 (2012)). En el mismo sentido, y siempre por vía ejemplar, en la sentencia recaída en la causa rol 1615-2010-INA, de 20 de enero de 2011, considerando décimo octavo, ha expresado que excluir a una persona "del beneficio de la asignación de título al restarle jerarquía a este por corresponder supuestamente a estudios de menor valor, supone discriminarlo en cuanto al disfrute de ese beneficio respecto de los titulares de otros diplomas a los que, por la naturaleza de los estudios que constatan, sí se les reconoce el derecho. Dicha diferencia es arbitraria, carece de razonabilidad e importa una infracción al principio de igualdad ante la ley consagrado en el número $2^{\circ}$ del artículo 19 de la Constitución Política” (ver artículo 35 de la Ley 
sin perjuicio de asociarla, acertadamente, también a algún otro derecho fundamental ${ }^{19}$.

Ahora bien, y en cuanto al concepto constitucional de discriminación, la doctrina y la jurisprudencia se encuentran contestes en entender que aquella tiene lugar cuando, intentando utilizar una noción que resuma las diversas fórmulas empleadas por tales fuentes, se está en presencia de una diferencia de trato que carece de lo que en el presente trabajo se denomina justificación admisible ${ }^{20}$.

En este sentido, entre los autores nacionales, Figueroa explica que habitualmente el término discriminar se utiliza en un sentido negativo, de modo que "suele significar separar o distinguir no debiendo hacerlo" ${ }^{21}$. Siguiendo a Nogueira, una discriminación es toda diferenciación hecha sobre fundamentos no razonables, irrelevantes o desproporcionados ${ }^{22}$. Para Evans se entiende por discriminación toda diferenciación o distinción que aparezca contraria a la ética elemental, o a un proceso normal de análisis intelectual, o que no tenga justificación racional o razonable ${ }^{23}$. Ahora en palabras de Silva Bascuñán, una discriminación es una diferencia sin fundamentación en la justicia natural o en la equidad más elemental ${ }^{24}$. Bronfman, Martínez y Núñez, por su parte, sostienen que el derecho a no ser discriminado ampara y protege frente a las diferencias arbitrarias, caprichosas, carentes de

18.962 y Decreto Ley No 479 de 1974, rol 1615 (2011)). Por último, y sin que estas referencias pretendan ser exhaustivas, en la sentencia recaída en la causa rol 1254-08-INC, de 29 de julio de 2009, considerando sexagésimo sexto, declaró que "la gratuidad del turno establecida en el inciso primero del artículo 595 del Código Orgánico de Tribunales, considerada en abstracto, infringe objetivamente la igualdad ante la ley y en particular la prohibición de discriminar arbitrariamente, en los términos que reconoce y ampara el artículo 19 , No 2o, de la Carta Fundamental y así se declarará” ver artículo 595 del Código Orgánico de Tribunales, rol 12542009.

19 Así, por ejemplo, la jurisprudencia del Tribunal Constitucional chileno ha vinculado la discriminación a la exigencia de prestaciones uniformes en materia de seguridad social. En este sentido dicho Tribunal sostuvo en la sentencia recaída en la causa rol 1985-2011-INA, de 26 de julio de 2011, considerando décimo sexto, que la norma que autoriza un encarecimiento de los planes de salud otorgado por las Instituciones de Salud Previsional en consideración a la edad potencia una discriminación que es contraria a la exigencia de prestaciones básicas y uniformes que establece el artículo 19, número 18, de la Constitución. Ver Artículos 38, inciso quinto de la Ley $\mathrm{N}^{\circ} 18.933$, en la parte que alude al factor etario; $2^{\circ}$ de la Ley $\mathrm{N}^{\circ} 20.015$, y 22 de la Ley sobre Efecto Retroactivo de las Leyes, rol 1985 (2011).

20 Como acertadamente explica Cobreros, la discriminación no solo se produce cuando hay diferencia de trato de lo igual, sino también cuando se otorga el mismo trato a lo desigual. En este último sentido, se habla de discriminación por indiferenciación, aunque también se han empleado la expresión "discriminación por indiscriminación”. Ver Cobreros (2007) pp. 71-114. La misma distinción entre estas dos clases de discriminación se puede encontrar en Fernández (2001) especialmente pp. 55-57.

21 Con acierto explica Figueroa que la expresión discriminar puede tener un sentido neutral y un sentido no neutral en términos morales o valorativos. En el primer caso se refiere a "separar o distinguir sin implicar nada acerca de si tal separación o distinción es correcta o incorrecta, cualquiera que sea el punto de vista”. Su significado no neutral puede presentar una connotación positiva, en cuyo caso se alude a una capacidad o aptitud intelectiva, o una connotación negativa, en el sentido de separar o distinguir no debiendo hacerlo. Ver FigueroA (2000) pp. 5 y 6.

22 Textualmente expresa el autor que el principio de no discriminación "prohíbe toda diferenciación hecha sobre fundamentos no razonables, irrelevantes o desproporcionados". NogueIra (2008) p. 227. La misma definición se encuentra en Nogueira (2006) p. 806.

23 Evans (2004) p. 125.

24 Silva (2006) p. 124. 
razonabilidad ${ }^{25}$. En fin, para Bulnes las discriminaciones son distinciones que no se fundan en la razón, en la justicia o no propendan al bien común ${ }^{26}$.

La doctrina constitucional comparada coincide con los autores nacionales. En este sentido, Jiménez afirma que la discriminación es, "en principio, la diferenciación desprovista de fundamento, sean cuales sean las «pruebas» o cánones de racionalidad que puedan aquí emplearse"27. Martín Cubas, por su parte, expresa que la discriminación consiste en que la desigualdad de tratamiento es injustificada por no ser razonable" 28 . En palabras de Mendonca y Guibourg, la discriminación es "una diferencia introducida (o no eliminada) sin justificación”29.

El Tribunal Constitucional chileno, por su parte, ha entendido por discriminación "una diferencia irracional o contraria a la razón" 30 , "una diferencia irracional o contraria al bien común" 31 , y, siguiendo a Evans, toda diferenciación o distinción contraria a la ética elemental o a un proceso normal de análisis intelectual; en otros términos, que no tenga justificación racional o razonable ${ }^{32}$.

\section{LOS REQUISITOS DEL CONCEPTO DE DISCRIMINACIÓN EN LA LEY 20.609}

La ley en comento incluye un concepto de lo que denomina discriminación arbitraria. Al respecto se dispone lo siguiente en el artículo $2^{\circ}$ : "Para los efectos de esta ley, se entiende por discriminación arbitraria toda distinción, exclusión o restricción que carezca de justificación razonable, efectuada por agentes del Estado o particulares, y que cause privación, perturbación o amenaza en el ejercicio legítimo de los derechos fundamentales establecidos en la Constitución Política de la República o en los tratados internacionales sobre derechos humanos ratificados por Chile y que se encuentren vigentes".

En consecuencia, la ley establece tres requisitos copulativos para determinar en qué caso se está frente a una discriminación. Ellos son (1) que se trate de una distinción, exclusión o restricción (2) que carezca de justificación razonable y (3) que cause privación, perturbación o amenaza en el ejercicio legítimo de los derechos fundamentales establecidos

25 De acuerdo con estos autores, el derecho a no ser discriminado "no implica que no se pueda diferenciar, pues este derecho ampara y protege frente a las diferencias arbitrarias, caprichosas, carentes de razonabilidad. En otros términos, la igualdad no impide establecer diferenciaciones, en la medida que estas sean razonables". Ver Bronfman et al. (2012) p. 95.

26 En realidad la autora no define "discriminaciones", sino "distinciones arbitrarias". No obstante, en este caso la palabra distinciones se utiliza en el sentido de discriminaciones. Ver Bulnes (2009) pp. 18 y 19.

27 JimÉNEZ (1983) p. 83.

28 Martin (1998) p. 161.

29 Mendonca y Guibourg (2004) p. 179.

30 En este sentido se pronuncia el Tribunal Constitucional chileno en las sentencias recaídas en las causas rol 1204-08-INA, de 28 de mayo de 2009, considerando décimo tercero, y rol 1217-08-INA, de 31 de enero de 2009, considerando octavo. Ver Artículo 1891 del Código Civil, rol 1204 (2009) y Artículo 104 de la Ley General de Bancos, rol 1217 (2009).

31 Estas expresiones son utilizadas por el Tribunal Constitucional de Chile en la sentencia recaída en la causa rol 811-2007, de 31 de enero de 2008, considerando vigésimo. Ver Artículo 107 de la Ley General de Bancos, rol 811 (2007).

32 Tribunal Constitucional chileno, sentencia recaída en la causa rol 811-2007, de 31 de enero de 2008, considerando vigésimo. Ver Artículo 107 de la Ley General de Bancos, rol 811 (2007). 
en la Constitución Política de la República o en los tratados internacionales sobre derechos humanos ratificados por Chile y que se encuentren vigentes. Es irrelevante si la conducta proviene de agentes del Estado o de particulares.

De este modo, y aun a riesgo de ser redundante, conviene advertir que la sola diferencia de trato, sea por distinción, exclusión o restricción, que carece de fundamento no es, desde el punto de vista de la ley, constitutiva de discriminación. Para serlo es necesario que, además, se produzca una lesión en el disfrute de derechos fundamentales otorgados por la Constitución o por tratados ratificados y vigentes.

\section{EVALUACiÓN DE LOS REQUisitos DEL CONCEPTO LEGAL DE DISCRIMINACIÓN}

Según se ha expresado, resulta posible sostener que tanto en el Derecho internacional como en el Derecho constitucional los elementos constitutivos del concepto de discriminación son dos: el establecimiento de una diferencia de trato y que esa diferencia de trato carezca de justificación admisible. Esta constatación confirma que la definición contenida en al ley añade un requisito que aquellas áreas del Derecho no consideran: la necesidad de que la diferencia carente de justificación vulnere derechos fundamentales estatuidos en la Constitución o en tratados ratificados y vigentes.

La divergencia de significados entre los Derechos internacional y constitucional, por una parte, y la ley contra la discriminación, por otra, carecería de relevancia jurídica si se limitara al plano conceptual. Sin embargo, este no es el caso. Quien es víctima de una diferencia de trato que carece de justificación admisible, pero sin vulneración de derechos fundamentales, sufre una discriminación desde el punto de vista del Derecho internacional de los derechos humanos y desde el punto de vista constitucional, pero no para la ley en análisis. En consecuencia, puede accionar de protección de conformidad con el artículo 20 de la Constitución y utilizar los recursos contemplados en el Derecho internacional, pero no puede utilizar la acción de no discriminación del artículo $3^{\circ}$ de la ley ${ }^{33}$.

De este modo, el concepto legal de discriminación, en cuanto incluye la exigencia de vulneración de derechos fundamentales, presenta a lo menos cuatro problemas. El primero de ellos es que vacía de contenido al derecho a la no discriminación, el que carece de relevancia jurídica si no se infringe algún otro derecho fundamental ${ }^{34}$. Por otra parte, disminuye la cantidad de casos tutelables por vía legal, respecto de los susceptibles de protección constitucional o internacional. En tercer lugar, impone exigencias probatorias adicionales a quien desea invocar la ley contra la discriminación, respecto de quien alega una discriminación en el marco de la Constitución o del Derecho internacional. Por último, y como con-

\footnotetext{
33 Esta afirmación supone compartir la sostenida por Pablo Llanquilef, quien expresa que la definición ofrecida por la ley "es vinculante solo para efectos de ese proyecto y no trasciende, al menos en lo que a la obligatoriedad respecta, a otros cuerpos normativos". LlanQUILEF (2012).

34 En similar sentido, expresa Hugo Tórtora: "Esta referencia a otros derechos fundamentales, priva al derecho a la discriminación de su carácter autónomo, lo cual nos parece de suma gravedad. Y es que sujetar la definición de un derecho, a la violación de otro, simplemente significa anular al primero, haciéndolo desaparecer del ordenamiento, afectándolo directamente en su núcleo esencial, en clara violación del artículo 19 numeral 26 de la Carta Fundamental". Ver Tórtora (2012).
} 
secuencia, genera un desincentivo al uso de la acción de no discriminación contemplada en la ley, frente a la acción de protección del artículo 20 de la Constitución.

\section{LA AMBIGUA REFERENCIA A LAS CATEGORÍAS SOSPECHOSAS}

La doctrina utiliza con cierta habitualidad las intercambiables expresiones "categorías sospechosas" 35 y "criterios sospechosos" 36 . Con ella se alude a ciertas propiedades ${ }^{37}$, características ${ }^{38}$, rasgos ${ }^{39}$ o condiciones ${ }^{40}$ predicables de las personas que en los hechos o en el Derecho han estado históricamente relacionadas con un trato discriminatorio ${ }^{41}$, como el sexo o la raza. A continuación se explicitará su significación en el Derecho internacional de los derechos humanos y en el Derecho constitucional, para revisar luego el modo en que han sido consideradas en la ley en análisis ${ }^{42}$.

\section{Las categorías Sospechosas en el Derecho internacional}

Dos son las ideas fundamentales formuladas desde el Derecho internacional respecto de las categorías sospechosas.

La primera de ellas es que se prohíbe la diferencia de trato basada en las propiedades consideradas categorías sospechosas. Así se sostiene, por ejemplo, en la Declaración Universal de Derechos Humanos ${ }^{43}$, en el Pacto ${ }^{44}$, en la Convención de los derechos del niño ${ }^{45}$, en la Declaración Americana de los derechos y deberes del hombre ${ }^{46}$ y en la Convención Americana ${ }^{47}$. Cada uno de estos instrumentos presenta un listado de criterios sospechosos, los

\footnotetext{
35 Ver, por ejemplo, Clérico y Aldao (2011) p. 161; y Contreras et al. (2010) p. 648.

36 Ver, por ejemplo, Nogueira (2006) pp. 817 y 818; y Bernal (2002) pp. 63-65.

37 La expresión propiedades es utilizada en AleXy (2001) pp. 384 y ss.

38 El término características es empleada en Comanducci (1999) pp. 84 y ss.

39 La palabra rasgos es utilizada en Rubio (1991) pp. 9-38.

40 Las expresiones "condición” y "condición social" son las habitualmente empleadas en el Derecho internacional de los derechos humanos. Al respecto ver, por ejemplo, el artículo 2 de la Declaración Universal de Derechos Humanos, los artículos 2 y 26 del Pacto, el artículo 2 de la Convención de los derechos del niño y los artículos 1 y 24 de la Convención Americana.

41 En este mismo sentido, la Corte Constitucional colombiana ha explicado en la sentencia T-1258/08, de 15 de diciembre, párrafo 4.1.3, que a estas propiedades o condiciones se les ha dado el nombre en la doctrina constitucional contemporánea de "categorías sospechosas", porque han estado ligadas históricamente a prácticas discriminatorias. Ver Henry Páez Guzmán c. Corte Constitucional y Sala Administrativa del Consejo Superior de la Judicatura, rol T-1258/08 (2008).

42 Conviene advertir que no existe consenso respecto de qué propiedades deben ser consideradas categorías sospechosas, ni respecto del criterio que permite determinar cuáles deben recibir tal denominación. Así lo muestra, por ejemplo, SABA (2008) pp. 698 y 699, al explicar los diversos criterios que ha utilizado la Corte Suprema de Justicia de Argentina para identificar tales categorías.

43 Artículo 2 de la Declaración Universal de Derechos Humanos.

44 Artículo 2 del Pacto.

45 Artículo 2 de la Convención de los derechos del niño.

46 Artículo II de la Declaración Americana de los derechos y deberes del hombre.

47 Artículos 1 y 24 de la Convención Americana.
} 
que por cierto no son taxativos ${ }^{48}$. Estas categorías también aparecen consagradas, aunque limitada a la propiedad de los sujetos a que se refiere el respectivo tratado, en la Convención Internacional sobre la eliminación de todas las formas de discriminación racial ${ }^{49}$, en la Convención sobre la eliminación de todas las formas de discriminación contra la mujer ${ }^{50}$, y en la Convención sobre los derechos de las personas con discapacidad ${ }^{51}$. En este mismo sentido, la Corte Interamericana ha sostenido que, a partir de lo dispuesto en el artículo 1 de la Convención Americana, los Estados tienen la obligación de garantizar el derecho a la igualdad ante la ley y la no discriminación "a sus ciudadanos y a toda persona extranjera que se encuentre en su territorio, sin discriminación alguna por su estancia regular o irregular, su nacionalidad, raza, género o cualquier otra causa" 52 .

Sin embargo, y esta es la segunda idea, no toda diferencia de trato fundada en las categorías sospechosas constituye discriminación. En este sentido el Comité de Derechos Humanos de Naciones Unidas ha observado que "el goce en condiciones de igualdad de los derechos y libertades no significa identidad de trato en toda circunstancia". De hecho, destaca el mismo Comité, el propio Pacto establece diferencias de trato basadas en tales criterios $^{53}$. En consecuencia, el artículo 26 del Pacto no prohíbe toda diferencia de trato, sino que exige que "cualquier diferencia debe basarse en criterios razonables y objetivos ${ }^{54}$.

En similar sentido, la jurisprudencia de la Corte Interamericana de Derechos Humanos permite concluir que la diferencia de trato basada en alguna de las categorías sospechosas no genera, necesariamente, una discriminación. Así, por ejemplo, una distinción en el otorgamiento de la nacionalidad que atiende a la nacionalidad de origen del solicitante no será discriminatoria si la facilita para aquellos que presentan lazos históricos, culturales y espirituales más estrechos con el país que regula dicha materia ${ }^{55}$. Del mismo modo, se

\footnotetext{
48 En efecto, los cinco instrumentos internacionales mencionados añaden, luego de indicar las diversas categorías o propiedades, las expresiones "cualquier otra condición”, "cualquier otra condición social” y "otra alguna”. La misma idea expresa la Corte Interamericana de Derechos Humanos cuando afirma que los criterios establecidos en la Convención Americana "no son un listado taxativo o limitativo sino meramente enunciativo. Por el contrario, la redacción de dicho artículo deja abiertos los criterios con la inclusión del término "otra condición social" para incorporar así a otras categorías que no hubiesen sido explícitamente indicadas”. Corte Interamericana de Derechos Humanos (2012) párrafo 85.

49 Artículo 1 de la Convención Internacional sobre la eliminación de todas las formas de discriminación racial, que establece como categorías sospechosas la raza, el color, el linaje y el origen nacional o étnico.

50 Artículo 1 de la Convención sobre la eliminación de todas las formas de discriminación contra la mujer, que establece como única categoría sospechosa precisamente el sexo.

51 Artículo 2 de la Convención sobre los derechos de las personas con discapacidad, que establece como única categoría sospechosa la discapacidad.

52 Corte Interamericana de Derechos Humanos (2005) párrafo 155.

53 Al respecto el Comité de Derechos Humanos de Naciones Unidas precisa que el párrafo 5 del artículo 6 prohíbe que "se imponga la pena de muerte a personas de menos de 18 años de edad. El mismo párrafo prohíbe que se aplique dicha pena a las mujeres en estado de gravidez. De la misma manera, en el párrafo 3 del artículo 10 se requiere que los delincuentes menores estén separados de los adultos. Además, el artículo 25 garantiza determinados derechos políticos, estableciendo diferencias por motivos de ciudadanía y de edad". Ver Comité de Derechos Humanos de Naciones Unidas (1989) párrafo 8.

54 Järvinen c. Finlandia (1990) párrafo 6.3. La misma doctrina se encuentra en Comité de Derechos Humanos de Naciones Unidas (1989), párrafo 13.

55 Corte Interamericana de Derechos Humanos (1984) párrafo 60.
} 
pueden establecer diferencias cuando se trata de la propiedad o característica consistente en pertenecer a una determinada etnia, pues los Estados deben otorgar a los pueblos indígenas una protección efectiva que tome en cuenta sus particularidades propias ${ }^{56}$. Incluso se permite un trato diferenciado entre migrantes documentados e indocumentados, o entre migrantes y nacionales, siempre que este trato diferencial sea razonable, objetivo, proporcional, y no lesione los derechos humanos ${ }^{57}$.

La consideración conjunta de las dos ideas recién desarrolladas permite concluir que no resulta posible establecer diferencias sobre la base de las categorías sospechosas, a menos que se cuente con una justificación admisible ${ }^{58}$. Sin embargo, y como cualquier diferencia de trato requiere una justificación admisible, en este caso el estándar o nivel de justificación debe ser todavía más alto o, si se prefiere, especialmente reforzado ${ }^{59}$. En consecuencia, desde el punto de vista del Derecho internacional de los derechos humanos, es posible afirmar que una diferencia de trato fundada en cualquiera de las propiedades mencionadas no es constitutiva, pero sí indiciaria de una discriminación.

En consecuencia, la regla es la prohibición de establecer diferencias fundadas en las categorías sospechosas y la excepción la permisión en caso que se cuente con una justificación reforzada. Esto significa una alteración en el onus probandi, pues al que ha realizado la diferenciación corresponderá probar la legitimidad de su acción ${ }^{60}$. En este sentido, el Comité de Derechos Humanos de Naciones Unidas ha declarado que, si "no se ha ofrecido justificación adecuada para esta diferencia”, no resulta admisible atender al sexo de una persona extranjera casada con un nacional, como criterio para que el Estado de este último confiera o prive del derecho de residencia a la primera ${ }^{61}$. Del mismo modo, rechazó los

56 Corte Interamericana de Derechos Humanos (2010) párrafo 270, con cita de otras tres sentencias en el mismo sentido en la nt. 298.

57 Corte Interamericana de Derechos Humanos (2003) párrafo 119.

58 Para efectos de evaluar la admisibilidad de la justificación resulta fundamental analizar el propósito o finalidad de la diferencia de trato establecida. Ver Oficina Regional para América Latina y el Caribe del Alto Comisionado de Naciones Unidas para los Derechos Humanos (2007) pp. 932 a 934.

59 En este mismo sentido, y luego de analizar el significado de la formulación clásica de la igualdad, que consiste en tratar de la misma manera a lo igual y de diversa manera a lo desigual, Alexy concluye: "la máxima general de igualdad puede ser interpretada en el sentido de un principio de igualdad que, prima facie, exige un tratamiento igual y solo permite un tratamiento desigual si puede ser justificado con razones opuestas". AleXY (2001) (nt. 39 p. 396 y p. 398).

60 En el mismo sentido, Patricia Palacios afirma que "el rechazo a distinciones fundadas en estas "categorías sospechosas" se ha convertido en norma de jus cogens internacional. Hasta el momento el referido consenso se ha centrado en el rechazo a diferenciaciones de trato basadas en la raza, el sexo o la religión de la persona. De esta manera se puede decir que hay una carga probatoria más pesada para aquellos que pretenden legitimar una medida que implica una desventaja para, por ejemplo, mujeres, africanos o judíos". Palacios (2006) pp. 36 y 37.

61 Caso Aumeeruddy-Cziffra c. Mauricio (1981). En el caso el Estado de Mauricio modificó las leyes de residencia de extranjeros casados con sus nacionales. Antes de la modificación legal, extranjeros de ambos sexos tenían derecho a residir en dicho Estado si habían contraído matrimonio con un mauriciano. Sin embargo, tras la modificación se privó de ese derecho a los varones casados con mauricianas. En una inequívoca muestra de la alteración del onus probandi, el Comité de Derechos Humanos expresó en el párrafo 9.2 b) 2 i). 8: "Es el goce de los derechos el que debe garantizarse sin discriminación. Basta aquí, por consiguiente, señalar que en la posición actual se hace una distinción adversa por motivos de sexo, que afecta a las presuntas víctimas en el goce de uno de sus derechos. No se ha ofrecido justificación adecuada para esta diferencia. El Comité debe, pues, encontrar que hay violación del párrafo 1 del artículo 2 y del artículo 3 del Pacto, juntamente con el párrafo 1 del artículo 17”. 
argumentos presentados por Francia para establecer una pensión de diverso valor para los soldados que le han prestado servicios por razón de nacionalidad ${ }^{62}$.

\section{Las CATEgorías SOSPECHOSAS EN El DeReCho CONSTITUCIONAL}

La Constitución chilena no contiene menciones expresas a las categorías sospechosas, como propiedades o condiciones conforme a las cuales se prohíbe discriminar ${ }^{63}$. Seguramente este silencio, que por cierto no es mirado con buenos ojos por el Comité de Derechos Humanos de Naciones Unidas ${ }^{64}$, explica tanto el escaso desarrollo jurisprudencial y doctrinario de la materia en Chile, como también las extendidas prácticas discriminatorias fundadas en alguno de los rasgos sospechosos que perviven en el país ${ }^{65}$. Con todo, esta omisión se puede considerar en algún sentido atenuada por dos disposiciones constitucionales del artículo 19, número 2. Una de ellas establece que hombres y mujeres son iguales ante la ley, mientras la otra prescribe que en Chile no hay persona ni grupo privilegiado.

62 Se trata del caso Gueye y otros v. Francia (1989). Aunque es un poco extenso, resulta conveniente transcribir el párrafo 9.5, en el que el Comité de Derechos Humanos va descartando los argumentos ofrecidos por Francia para acreditar la objetividad y racionalidad de la diferencia de trato: "el Comité señala que no fue la cuestión de la nacionalidad la que determinó que se concedieran pensiones a los autores, sino los servicios que habían prestado en el pasado. Habían prestado servicios en las fuerzas armadas francesas en las mismas condiciones que los ciudadanos franceses; durante 14 años después de la independencia del Senegal, fueron tratados de la misma manera que sus colegas franceses para los fines de los derechos de pensión, aunque no eran de nacionalidad francesa sino senegalesa. No se puede considerar que un cambio posterior de nacionalidad justifique en sí una diferencia de trato, ya que la base para la concesión de la pensión fueron los mismos servicios que prestaron tanto ellos como los soldados que siguieron siendo franceses. Ni tampoco se pueden invocar como justificación legítima las diferencias en la situación económica, financiera y social de Francia y del Senegal. Si se compara el caso de los soldados de nacionalidad senegalesa retirados residentes en el Senegal con la de los soldados de nacionalidad francesa retirados que viven en el Senegal, se verá que aquéllos parecen vivir en las mismas condiciones económicas y sociales. Y sin embargo, el trato que recibirían unos y otros a los efectos de los derechos de pensión sería diferente. Por último, el hecho de que el Estado Parte alegue que ya no le resulta posible comprobar identidades y situaciones familiares a fin de impedir abusos en la administración de los planes de pensión no puede justificar una diferencia de trato. En opinión del Comité, no cabe invocar una simple inconveniencia de tipo administrativo, ni la posibilidad de que se cometa algún abuso respecto de los derechos a las pensiones, para justificar un trato desigual. El Comité llega a la conclusión de que la diferencia en el trato de los autores no se basa en criterios razonables y objetivos y que constituye una discriminación prohibida por el Pacto".

63 Pese al silencio de la Constitución, resulta posible encontrar referencia a las categorías sospechosas en otras disposiciones del ordenamiento jurídico chileno: en el artículo $8^{\circ}$ de la ley 19.253 , que establece normas sobre protección, fomento y desarrollo de los indígenas, y crea la Corporación Nacional de Desarrollo Indígena, en el artículo $2^{\circ}$ del Código del Trabajo, cuyo texto refundido, coordinado y sistematizado fue fijado por el decreto con fuerza de ley 1, de 2002, del Ministerio del Trabajo y Previsión Social, y en el artículo 17 de la ley 18.834, sobre Estatuto Administrativo, cuyo texto refundido, coordinado y sistematizado fue fijado por el decreto con fuerza de ley 29, de 2004, del Ministerio de Hacienda.

64 El Comité de Derechos Humanos de Naciones Unidas "ha observado que en algunas constituciones y leyes no se señalan todos los motivos por los que se prohíbe la discriminación, en la forma en que se enumeran en el párrafo 1 del artículo 2. Por lo tanto, el Comité desearía recibir información de los Estados Partes en cuanto al significado que revisten esas omisiones". Comité de Derechos Humanos de Naciones Unidas (1989) párrafo 11.

65 Frente a ese silencio, Nogueira reclama la necesidad de regular de manera explícita la "prohibición de mantener determinadas diferenciaciones históricamente arraigadas y que han situado, tanto por la acción de los órganos estatales como por la práctica social, a sectores de la población en posiciones marginales o altamente desventajosas, cuando no atentatorias contra la dignidad humana. Así ha ocurrido matizadamente con las diferencias de género y los pueblos originarios de nuestros países latinoamericanos”. NogueIra (2008) pp. 247 y 248. 
En efecto, mientras en la primera de ellas hay referencia al sexo, en la segunda estarían implícitos los demás criterios sospechosos.

Pese al ya mencionado escaso desarrollo jurisprudencial y doctrinario en esta materia, es posible afirmar que la reflexión jurídica chilena existente se orienta en el mismo sentido que el Derecho internacional de los derechos humanos.

En efecto, por regla general se prohíbe atender a tales categorías para establecer diferencias de trato entre las personas. $\mathrm{Al}$ respecto, y habitualmente fundándose en el principio de igualdad en la ley, el Tribunal Constitucional con frecuencia ha aludido a las categorías sospechosas. Aunque su jurisprudencia no ofrece una reflexión acabada, se infiere de manera inequívoca que las rechaza como criterios a partir de los cuales establecer diferencias de trato. En este sentido reiteradamente ha expresado que "la edad, sexo, raza, origen social o nacional", "la condición social, la posición económica o las creencias del demandado" son categorías que pueden resultar inaceptables para establecer diferencias ${ }^{66}$. Más restringidamente, aunque en igual dirección, también ha sostenido que "es un lugar común sostener que toda discriminación fundada en raza, sexo o clase es contraria a derecho"67.

En el mismo sentido se orienta la doctrina nacional. Así, Contreras, García, Jordán y Villanueva han explicado que la prohibición de discriminación sobre la base de las categorías mencionadas en el artículo 26 del Pacto recoge el contenido constitucional del principio de igualdad ${ }^{68}$. Con igual inspiración, aunque aludiendo a una sola de las propiedades sospechosas, Silva Bascuñán ha expresado que la Constitución al afirmar la igualdad humana la refiere con alcance semejante al hombre y la mujer, de modo que aquella condena, por lo tanto, la distinción entre ambos ${ }^{69}$.

Sin embargo, y al mismo tiempo, la jurisprudencia y la doctrina chilenas matizan su inicial rechazo al uso de los criterios sospechosos para fundar una diferencia de trato, siempre que al efecto se cuente con una justificación admisible. En este sentido el Tribunal Constitucional ha estimado conforme con la Constitución la exclusión de las personas que padecen discapacidad cuando se debe completar el mínimo de vocales necesarios para el funcionamiento de las mesas receptoras de sufragios ${ }^{70}$. Del mismo modo, ha declarado constitucional que las medidas alternativas a las penas privativas o restrictivas de libertad

66 La referencia a esas categorías se puede apreciar, por ejemplo, en las sentencias del Tribunal Constitucional de Chile recaídas en las causas rol 1876-2011-INA, de 9 de agosto de 2011, considerando trigésimo cuarto; rol 1217-08-INA, de 31 de enero de 2009, considerando décimo primero (sic); rol 1204-08-INA, de 28 de mayo de 2009, considerando undécimo (sic); y rol 811-2007, de 31 de enero de 2008, considerando décimo primero (sic). Ver Artículo 8, inciso primero, de la Ley No 17.322, rol 1876 (2011), Artículo 104 de la Ley General de Bancos, rol 1217 (2009), Artículo 1891 del Código Civil, rol 1204 (2009) y Artículo 107 de la Ley General de Bancos, rol 811 (2007).

67 Sentencia del Tribunal Constitucional de Chile recaída en la causa rol 986-2007, de 30 de enero de 2008, considerando trigésimo tercero. Ver artículo 387, inciso segundo, del Código Procesal Penal, rol 986 (2008).

68 Contreras et al. (2010) pp. 633-674, p. 654.

69 Silva (1997) p. 28.

70 La sentencia del Tribunal Constitucional de Chile recaída en la causa rol 2152 -2011-CPR, de 19 de enero de 2012, declaró constitucional la siguiente modificación al artículo 57 de la ley 18.700: "A partir de las nueve horas el Delegado procederá a designar los vocales que faltaren hasta completar solo el mínimo necesario para funcionar, de entre los electores alfabetos no discapacitados que deban sufragar en el recinto". Ver Proyecto de ley sobre inscripción automática, Servicio Electoral y sistema de votaciones, rol 2152 (2012). 
sean diversas para los extranjeros que no tengan residencia legal en Chile ${ }^{71}$. Igualmente, ha sostenido la plena conformidad constitucional de establecer diferencias en la forma de participación en la toma de decisiones atendiendo al origen étnico de las personas ${ }^{72}$. Verdugo y Pfeffer, por su parte, admiten que el legislador y la autoridad establezcan diferencias en el ámbito jurídico "entre chilenos y extranjeros, entre mayores y menores de edad, hombre o mujer (sic), entre civiles y militares, entre empleados públicos y particulares, etc."73.

Todas estas diferencias de trato son admisibles porque, según ha declarado el Tribunal Constitucional, la Constitución no prohíbe hacer diferencias, ni siquiera fundadas en las mencionadas categorías sospechosas, sino hacer diferencias arbitrarias ${ }^{74}$, de modo que la distinción "debe ser legítima y razonable, es decir, proveer una relación instrumental o de funcionalidad entre el fin perseguido por la norma y el criterio escogido para justificar el trato diferente" 75 . Esta perspectiva es acertada si se considera que la propia Constitución establece diferencias de trato fundadas, por ejemplo, en la nacionalidad al otorgar el derecho de sufragio ${ }^{76}$, en la profesión para ejercer ciertas funciones públicas ${ }^{77}$, en el nivel educacional para efectos de ser Senador ${ }^{78}$, y en la edad para ser Presidente de la República ${ }^{79}$, Ministro de Estado ${ }^{80}$, Diputado ${ }^{81}$ o Senador ${ }^{82}$, o para conceder la ciudadanía ${ }^{83}$.

En este sentido, la relevancia de incluir una determinada propiedad entre las categorías sospechosas es que coloca el peso de la justificación en quien ha establecido diferencias de trato basadas en dicha propiedad. Al respecto Roberto Saba explica que al calificarse una

\footnotetext{
71 La sentencia del Tribunal Constitucional chileno recaída en la causa rol 2230-2012-CPR, de 5 de junio de 2012, declaró constitucional la siguiente disposición introducida a la ley 18.216: "Artículo 34.- Si el condenado a una pena igual o inferior a cinco años de presidio o reclusión menor en su grado máximo fuere un extranjero que no residiere legalmente en el país, el juez, de oficio o a petición de parte, podrá sustituir el cumplimiento de dicha pena por la expulsión de aquél del territorio nacional”. Ver Proyecto de ley que modifica la ley N 18.216, rol 2230 (2012).

$72 \mathrm{Al}$ respecto el Tribunal Constitucional de Chile declaró en la sentencia recaída en la causa rol 1050-CPR, de 3 de abril de 2008, considerando décimo quinto, que "la posibilidad de participación que las normas en análisis del Convenio [169 de la Organización Internacional del Trabajo] entregan a los pueblos indígenas no pugnan con el principio de participación con igualdad de oportunidades en la vida nacional, que consagra el artículo $1^{\circ}$ de la Carta Fundamental, toda vez que ellas disponen, para un grupo socioeconómicamente vulnerable, con la especificidad histórica cultural que le es propia, un mecanismo de participación que no tiene carácter vinculante". Ver Proyecto de acuerdo aprobatorio relativo al Convenio No 169 sobre pueblos indígenas, rol 1050 (2008).

73 Verdugo et al. (2002) p. 215.

74 En este sentido se ha pronunciado el Tribunal Constitucional de Chile en la sentencia recaída en la causa rol 807-07-INA, de 4 de octubre de 2007, considerando vigésimo segundo. Ver Letra d) del artículo 17, y del artículo 19 de la Ley $\mathrm{N}^{\circ}$ 18.216, rol 807 (2007).

75 Sentencia del Tribunal Constitucional de Chile recaída en la causa rol 1873-2010-INA, de 25 de agosto de 2011, considerando decimotercero. Ver Inciso segundo del artículo 768 del Código de Procedimiento Civil, rol 1873 (2011). En similar sentido, Silva (1997) p. 28; y Verdugo et al. (2002) p. 215.

76 Artículos 13 y 14 de la Constitución chilena.

77 Artículos 77, 78, 85, 86, 88, 92, 96 y 98 de la Constitución chilena.

78 Artículo 50 de la Constitución chilena.

79 Artículo 25 de la Constitución chilena.

80 Artículo 34 de la Constitución chilena.

81 Artículo 48 de la Constitución chilena.

82 Artículo 50 de la Constitución chilena.

83 Artículo 13 de la Constitución chilena.
} 
categoría como sospechosa se coloca al autor de la distinción "en una situación de desventaja frente a quien denuncia el trato desigual inconstitucional. Este último básicamente deberá esperar que el acusado demuestre que la presunción en su contra no se sostiene" 84 . De este modo, desde el punto de vista del Derecho constitucional resulta posible sostener que, en principio, no es admisible establecer diferencias basadas en alguna de las categorías sospechosas, a menos que se cuente con una justificación admisible especialmente reforzada para ello. En otras palabras, y reiterando lo expresado al analizar este mismo asunto en el Derecho internacional, las diferencias fundadas en los criterios sospechosos no son constitutivas, pero sí indiciarias de discriminación.

\section{ReFERENCiA A LAS CATEgorías SOSPECHOSAS EN LA LEY 20.609}

La ley en comentario entiende que se produce una discriminación cuando se establece una distinción, exclusión o restricción que carece de justificación razonable y que afecta derechos fundamentales estatuidos en la Constitución o en los tratados ratificados y vigentes, "en particular cuando se funden en motivos tales como la raza o etnia, la nacionalidad, la situación socioeconómica, el idioma, la ideología u opinión política, la religión o creencia, la sindicación o participación en organizaciones gremiales o la falta de ellas, el sexo, la orientación sexual, la identidad de género, el estado civil, la edad, la filiación, la apariencia personal y la enfermedad o discapacidad".

Como se puede advertir, luego de precisar cuándo se produce una discriminación arbitraria, la ley añade que ello ocurre "en particular" cuando se funda en las propiedades, características, rasgos o criterios mencionados. Sin embargo, la expresión elegida para hacer el enlace entre la definición y las propiedades mencionadas ("en particular") no permite precisar cuál es el rol que cumplen los tales criterios en la configuración de una discriminación y da lugar a diversas interpretaciones. Esas interpretaciones son, al menos, las siguientes:

a) Una posibilidad es que sustituyan las exigencias de falta de justificación razonable y la lesión de derechos fundamentales, es decir, los dos últimos requisitos del concepto. Desde esta atribución de significado, se estaría frente a una discriminación si se produce una distinción, exclusión o restricción basada en tales propiedades, sin excepción.

b) Otra posibilidad es que la consideración de aquellas propiedades sustituya la exigencia de lesión de derechos fundamentales, es decir, el tercero de los elementos de la definición. En tal caso se produciría una discriminación si se incurre en una distinción, exclusión o restricción que carezca de justificación razonable y que se funde en las propiedades aludidas, aun cuando no se afecten derechos fundamentales.

c) Por otra parte, sería posible entender que el listado de propiedades sustituye la exigencia conceptual de falta de justificación razonable, esto es, el segundo requisito del concepto. Esta interpretación conduciría a concluir que existe discriminación si la distinción, exclusión o restricción lesiona derechos fundamentales y se basa en alguna de las características señaladas, aun cuando cuente con una justificación admisible.

84 SABA (2008) pp. 695-742. 
d) Incluso sería posible entender que la expresión "en particular" es sinónimo de "por ejemplo", en cuyo caso las propiedades enumeradas en la ley serían meramente ilustrativas. De este modo, tampoco se sustituiría algún requisito del concepto de discriminación y el listado estaría absolutamente abierto a cualquier propiedad o característica. Esta interpretación es, como se puede advertir, incompatible con la noción de categorías sospechosas.

e) Una última posibilidad consiste en asimilar la expresión "en particular" con "en especial”, con lo que se entendería que hay discriminación de manera singular cuando se establece una diferencia de trato fundada en las mencionadas categorías. En este caso no se sustituiría ningún requisito del concepto de discriminación, sino que se exigiría una argumentación reforzada a quien ha considerado alguna de tales propiedades para establecer una diferencia de trato.

Más allá de las preferencias que pueda despertar alguna de las interpretaciones señaladas, todas ellas son posibles. De este modo, la ambigua referencia a las categorías sospechosas, singularmente debido a la expresión "en particular", impide determinar el impacto que tienen en el concepto de discriminación ofrecido por la ley.

Sin embargo, no todas esas interpretaciones resultan consistentes con el Derecho internacional de los derechos humanos y con el Derecho constitucional. En efecto, y según se ha mostrado, ambos sistemas normativos rechazan las diferencias de trato basadas en las categorías sospechosas. Solo si se ofrece una justificación reforzada, la distinción, exclusión, restricción o preferencia podría ser considerada legítima. En igual sentido, explica Patricio Zapata: "el que una categoría sea sospechosa no significa que siempre, a todo evento, su empleo será contrario a la Constitución. La constatación de haberse usado por alguna autoridad o persona este tipo de categorías hace presumir, sí, la posible existencia de una discriminación. Se impone, por tanto, para destruir esa presunción, una muy buena justificación por parte de quien ha recurrido a estos criterios sospechosos y, en el caso de los jueces, un tipo de escrutinio muy estricto" 85 .

A la misma conclusión permite arribar la consideración de alguna jurisprudencia comparada. Así, por ejemplo, la Corte Suprema de Estados Unidos estableció ya en 1944 que toda restricción de los derechos civiles a un grupo racial es inmediatamente sospechoso. Y precisó que esto no significaba afirmar que todas estas restricciones son inconstitucionales, sino que las Cortes deben efectuar el más estricto de los escrutinios ${ }^{86}$. En similar sentido, la Corte Constitucional de Colombia ha precisado que en el caso de diferencias de trato esta-

\footnotetext{
85 Intervención de Patricio Zapata ante la Comisión de Constitución del Senado, durante el segundo trámite constitucional del proyecto de ley que dio lugar a la ley 20.609. Ver Biblioteca del Congreso Nacional, Historia de la ley 20.609, p. 677.

86 Textualmente afirmó la Corte Suprema de Estados Unidos: "It should be noted, to begin with, that all legal restrictions which curtail the civil rights of a single racial group are immediately suspect. That is not to say that all such restrictions are unconstitutional. It is to say that courts must subject them to the most rigid scrutiny. Pressing public necessity may sometimes justify the existence of such restrictions; racial antagonism never can" (Karumatsu v. United States, 323 U.S. (1944) 214.
} 
blecidas sobre la base de categorías sospechosas la carga de la prueba de la legitimidad de la medida se traslada a quien la aplica y que tales medidas se presumen inconstitucionales ${ }^{87}$.

Conviene reconocer que no fue esta la inteligencia dada por los parlamentarios a las categorías sospechosas. Durante la tramitación del respectivo proyecto de ley habitualmente se entendió que su referencia era meramente ejemplar. De este modo, cualquier otra propiedad o característica personal podía ser añadida a las anteriores e invocada con igual efecto para alegar una discriminación ${ }^{88}$. Sin embargo, esta interpretación no resulta, según se ha visto, coherente con el impacto jurídico que se atribuye a las categorías sospechosas en el Derecho Internacional de los derechos humanos, en el Derecho constitucional nacional o en el Derecho comparado ${ }^{89}$.

\section{Evaluación de la ReFERENCia a las Categorías SOSPECHOSAS EN LA LEY}

La revisión de los aportes del Derecho internacional de los derechos humanos y del Derecho constitucional chileno permitió concluir que las diferencias de trato fundadas en las categorías sospechosas solo son admisibles si cuentan con una justificación admisible especialmente reforzada. Frente a ello, la ley dispone que se produce una discriminación cuando se establece una distinción, exclusión o restricción que carece de justificación razonable y que afecta derechos fundamentales estatuidos en la Constitución o en los tratados ratificados y vigentes, "en particular" cuando se funden en alguna de las categorías sospechosas que indica.

Ese contraste permite evidenciar que frente a la comprensión existente en el Derecho constitucional chileno y, aún más claramente, en el Derecho internacional respecto de las categorías sospechosas, la ley contiene un enunciado normativo en que la referencia a tales categorías es ambigua. Frente al avance de aquellas áreas del Derecho, una tal indeterminación es inadmisible. De este modo no se puede concluir sino que la redacción de la ley ha generado un problema interpretativo y, por lo mismo, una nueva dificultad para la aplicación de la acción procesal contemplada en la misma. En efecto, la ambigua referencia a las categorías sospechosas provocará que cada tribunal les asigne un rol diverso en la con-

87 Así lo sostuvo la Corte Constitucional de Colombia en la sentencia T-340/10, de 11 de mayo de 2010, en los párrafos 52 y 53. Ver Manuel Moreno Rodríguez c. la Gobernación del Cesar (Secretaría de Deporte y Recreación), rol T-340/10 (2010).

88 En este sentido se pronunciaron, por ejemplo, las senadoras Soledad Alvear y Ximena Rincón, y los senadores Jovino Novoa, Hernán Larraín y Mariano Ruiz-Esquide en la discusión en Sala, en segundo trámite constitucional (ver Biblioteca del Congreso Nacional, Historia de la ley 20.609, pp. 815, 827, 830, 836 y 837, y 837 y 838, respectivamente). Y lo mismo los senadores Alberto Espina y Patricio Walker en la discusión en sala del proyecto propuesto por la Comisión Mixta (ver Biblioteca del Congreso Nacional, Historia de la ley 20.609, pp. 1163, y 1172 y 1173 , respectivamente).

89 Es necesario reconocer que el senador Orpis advirtió que la referencia a las categorías sospechosas implicaba alterar el onus probandi en contra del que había sido demandado por incurrir en una conducta discriminatoria. En la discusión en la Sala, en segundo trámite constitucional, sostuvo a este respecto: "Por eso, señor Presidente, soy partidario de mantener la definición de discriminación arbitraria, pero eliminando toda clase de categorías, de modo que ninguna tenga un carácter superior o sospechoso, por cuanto ello implica invertir la carga de la prueba en términos tales que toda persona demandada deba demostrar su inocencia. Su eliminación nos deja a todos en exacta igualdad de condiciones para evitar cualquier tipo de discriminación arbitraria”. Biblioteca del Congreso Nacional, Historia de la ley 20.609, p. 801. 
figuración de una discriminación, dependiendo del modo en que interpreten la imprecisa expresión "en particular" utilizada por la ley.

\section{LA NO DISCRIMINACIÓN COMO DERECHO SUBORDINADO}

\section{Jerarquía de la no disCriminación en el Derecho internaCional}

Según se ha destacado más arriba, la no discriminación es, simultáneamente, un derecho protector de otros derechos humanos y un derecho humano autónomo. Es en virtud de aquel carácter tutelar, expresado en diversos instrumentos internacionales ${ }^{90}$, que el Comité de Derechos Humanos de Naciones Unidas ha explicado que la no discriminación constituye un principio básico y general relativo a la protección de los derechos humanos ${ }^{91}$. Y es considerando su dimensión de derecho humano autónomo que el mencionado Comité ha sostenido que "los Estados deben tomar medidas contra la discriminación por agentes públicos y privados en todos los ámbitos" 92 y la Corte Interamericana ha declarado que los "Estados están obligados a adoptar medidas positivas para revertir o cambiar situaciones discriminatorias existentes en sus sociedades, en perjuicio de determinado grupo de personas"93.

Pues bien, bajo ninguna de las dos facetas resulta posible sostener que la prohibición de discriminar se subordina a alguno de los demás derechos conferidos por el Derecho internacional. De hecho, incluso se podría afirmar que se encuentra en un nivel preferente respecto de otros derechos si se considera que se trata de un principio de ius cogens. En efecto, la Corte Interamericana de Derechos Humanos ha sostenido de manera categórica que el principio de no discriminación "pertenece al jus cogens, puesto que sobre él descansa todo el andamiaje jurídico del orden público nacional e internacional”. Precisando esta perspectiva, ha añadido que "es un principio fundamental que permea todo ordenamiento jurídico". Por ello, concluye, en la actualidad "no se admite ningún acto jurídico que entre en conflicto con dicho principio fundamental" $"$.

Por otra parte, también se mencionaron con anterioridad las condiciones bajo las cuales una diferencia de trato no constituye discriminación. En la doctrina del Comité de Derechos Humanos de Naciones Unidas esas condiciones son tres: que los motivos o criterios para establecer la diferencia sean objetivos y razonables, y que la finalidad sea legítima o proporcionada. De las tres exigencias mencionadas "el de razonabilidad es el que más lugar ocupa en la jurisprudencia del Comité. La importancia del supuesto relativo a la licitud del propósito varía de un caso a otro, mientras que el supuesto de objetividad raras veces influye en sus decisiones" 95 . La Corte Interamericana, por su parte, en la que se puede considerar su

\footnotetext{
90 Artículo 1 de la Declaración Universal de Derechos Humanos, artículo 2 del Pacto, artículo II de la Declaración Americana de los Derechos y Deberes del Hombre, y artículo 1 de la Convención Americana, entre otros.

91 Comité de Derechos Humanos de Naciones Unidas (1989) párrafo 1.

92 Comité de Derechos Humanos de Naciones Unidas (2000) párrafo 31.

93 Corte Interamericana de Derechos Humanos (2012) párrafo 80.

94 Corte Interamericana de Derechos Humanos (2003) párrafo 101. Similar doctrina se puede encontrar en Corte Interamericana de Derechos Humanos (2012) párrafo 79 y Corte Interamericana de Derechos Humanos (2010) párrafo 269.

95 Oficina Regional para América Latina y el Caribe del Alto Comisionado de Naciones Unidas para los Derechos Humanos (2007) p. 932.
} 
doctrina más sólida, ha utilizado similares criterios al exigir que la medida se funde en motivos objetivos, razonables y legítimos o proporcionados respecto de la finalidad a alcanzar ${ }^{96}$.

En suma, en el contexto del Derecho internacional de los derechos humanos no resulta posible sostener que la prohibición de discriminar se encuentre subordinada a otros derechos. Lejos de ello, se le considera un principio fundamental. Por tanto, no es la presencia de otros derechos lo que impide que una diferencia de trato sea discriminatoria, sino la existencia de una justificación admisible, es decir, si existe razonabilidad, objetividad y legitimidad o proporcionalidad en dicha diferencia de trato.

\section{Jerarquía de la no discriminación en el Derecho CONSTITUCIONAL}

La Constitución chilena regula la prohibición de discriminar como una protección de otros derechos conferidos por aquella ${ }^{97}$ y como un derecho autónomo ${ }^{98}$. Por tanto, se puede exigir la tutela constitucional tanto en caso de trato discriminatorio en el goce de esos otros derechos de jerarquía constitucional como frente a tratos discriminatorios en sí mismos ${ }^{99}$. Pues bien, en ninguno de los dos casos la prohibición de discriminar aparece subordinada a algún otro derecho en el texto constitucional, ni resulta posible entenderla implícita en el mismo.

Por otra parte, la doctrina mayoritaria coincide en que, en abstracto, no existe jerarquía entre los derechos conferidos por la Constitución ${ }^{100}$. Por tanto, la no discriminación, en cuanto derecho autónomo, se encuentra en la misma grada o nivel normativo que los demás derechos constitucionales. Esto significa que, en caso de colisión entre la no discriminación y otros derechos constitucionales, no resulta posible establecer una preferencia general o incondicionada a favor de alguno de estos últimos.

Lo recién expresado no significa que las colisiones entre la prohibición de discriminar y otros derechos de jerarquía constitucional (y, en general, las colisiones entre derechos

96 Corte Interamericana de Derechos Humanos (2003) párrafo 119. Sin embargo, de manera singularmente más vaga, también ha utilizado como criterios de valoración de un trato diferenciado la justicia, la naturaleza de las cosas, en fin, que no se persigan "fines arbitrarios, caprichosos, despóticos o que de alguna manera repugnen a la esencial unidad y dignidad de la naturaleza humana". Ver Corte Interamericana de Derechos Humanos (1984) párrafo 57.

97 La discriminación está prohibida tanto de manera directa, como indirecta por la Constitución. De manera directa en el ámbito laboral (artículo 19, número 16) y en el trato que debe dar el Estado en materia económica (artículo 19, número 22). De manera indirecta al exigir, por ejemplo, el trato igualitario en la protección en el ejercicio de los derechos (artículo 19, número 3) y en el acceso a las acciones de promoción, protección y recuperación de la salud, y rehabilitación del individuo (artículo 19, número 9).

98 El artículo 19, número 2, de la Constitución prohíbe que la ley o autoridad alguna establezcan diferencias arbitrarias.

99 Los mecanismos constitucionales de tutela aplicables son la acción de protección (artículo 20), el requerimiento ante el Tribunal Constitucional (artículo 93, especialmente números 2 y 3), la acción de inaplicabilidad (artículo 93, número 6) y la acción de inconstitucionalidad (artículo 93, número 7).

100 José Luis Cea Egaña es, seguramente, el más reconocido representante de la doctrina que minoritariamente se pronuncia en sentido contrario. Insistiendo en una tesis que ha sostenido por largo tiempo, afirma que "tiene que admitirse la idea de jerarquía o gradación, de primacía o preponderancia de unos sobre otros de esos derechos" (las negritas son del texto citado). Luego propone una gradación más o menos genérica, para concluir sosteniendo que "en la enumeración del artículo 19 no están los derechos al azar, sino que ordenados siguiendo la secuencia jerárquica enunciada”. Ver CEA (2004) p. 66. 
constitucionales) carezcan de solución. Para resolver tal clase de problemas existe una herramienta denominada máxima, criterio o principio de proporcionalidad. Se trata de un instrumento reconocido y utilizado por los Tribunales Constitucionales de Alemania ${ }^{101}$, España $^{102}$ y Colombia ${ }^{103}$, y por el Tribunal Supremo de México ${ }^{104}$, entre otros, cada vez más utilizado por el Tribunal Constitucional chileno ${ }^{105}$, que en suma permite establecer una relación de precedencia condicionada entre los derechos en pugna a partir de las características del caso concreto ${ }^{106}$.

Por último, el Tribunal Constitucional chileno ha sostenido que los criterios que permiten determinar si una diferencia de trato es admisible o, por el contrario, constituye discriminación, son similares a las establecidas en el Derecho internacional. Así, desde sus primeras sentencias ha destacado el criterio de la razonabilidad, el que sigue empleando en la actualidad ${ }^{107}$. En los últimos años se han añadido el criterio de objetividad ${ }^{108} \mathrm{y}$, con ma-

101 Al efecto ver, por ejemplo, CLÉrico (2009).

102 Singularmente expresivo a este respecto es Sarmiento cuando expresa: "Desde hace aproximadamente quince años, el Derecho público español vive cada vez más pendiente de la evolución del principio de proporcionalidad. A pesar de la antigüedad de esta máxima y sus implicaciones filosóficas, que evidentemente van más allá de lo estrictamente jurídico, nuestro ordenamiento ha presenciado una preeminencia de la proporcionalidad hasta unos extremos sin duda desconocidos en nuestra historia legal. No solo el Tribunal Constitucional ha incorporado a su arsenal jurisprudencial las virtualidades del principio, sino también la jurisdicción contenciosoadministrativa, hasta hacer del mismo una norma que lo controla todo". SARMiento (2003) p. 145.

$103 \mathrm{Al}$ respecto puede verse BeRnAL (2002) pp. 51 a 74.

104 Ver SÁnchez (2010) especialmente pp. 333-342.

105 No resulta posible obviar que el Tribunal Constitucional chileno parece haber iniciado la aplicación del principio de proporcionalidad en forma sostenida. Así se puede advertir, por ejemplo, en Artículo 38 ter de la Ley de Isapres, rol 1710 (2010), considerando centésimo, Artículo único de la Ley No 20.028, rol 1452 (2010), considerando vigésimo octavo, y Proyecto de ley, aprobado por el Congreso Nacional, que fortalece y perfecciona la jurisdicción tributaria, rol 1243 (2008), considerando vigésimo tercero, en todas las cuales se señalan expresamente todas o algunas de las tres reglas constitutivas de la proporcionalidad, esto es, la adecuación, la idoneidad y la ponderación. Sin embargo, Zúñiga Añasco estima que "este órgano no ha sido capaz de construir una dogmática en materia de proporcionalidad que satisfaga los requisitos de estabilidad, coherencia y refinamiento conceptual exigibles a un intérprete privilegiado de la Constitución”. Al respecto ver ZúNína (2010) p. 270.

106 La relación de precedencia condicionada "consiste en que, tomando en cuenta el caso, se indican las condiciones bajo las cuales un principio precede al otro. Bajo otras condiciones, la cuestión de la precedencia puede ser solucionada inversamente". Alexy (2001) p. 92.

107 Respecto de la razonabilidad como criterio para evaluar la constitucionalidad de un tratamiento diferenciado, expresó en una de sus primeras sentencias, recaída en la causa rol 53, de 5 de abril de 1988, considerando 73 , que "se ha concluido que "la razonabilidad es el cartabón o standard de acuerdo con el cual debe apreciarse la medida de igualdad o la desigualdad". Este criterio se ha utilizado desde entonces en diversas sentencias incluyendo, entre las más recientes, la recaída en la causa rol 1988-2011 CPT, de 24 de junio de 2011, considerando sexagésimo cuarto, y la pronunciada en la causa rol 1812 (1816-1817)-10-CAA, de 18 de agosto de 2011, considerando vigésimo sexto. Al respecto ver Proyecto de ley orgánica constitucional sobre votaciones populares y escrutinios, rol 53 (1988), Convenio Internacional para la Protección de Obtenciones Vegetales (UPOV-91), rol 1988 (2011) y Artículo $7^{\circ}$ del Auto Acordado sobre tramitación y fallo del recurso de protección de garantías constitucionales de la Corte Suprema, rol 1912 (1916-1817) (2011).

108 El criterio de la objetividad se menciona, por ejemplo, en la sentencia recaída en la causa rol 1133-08-INA, de 18 de noviembre de 2008, considerandos décimo octavo y vigésimo séptimo. Ver Artículo 61 de la Ley oo 20.000, rol 1133 (2008). 
yor frecuencia, el de proporcionalidad de la finalidad perseguida por el legislador ${ }^{109}$, como criterios para evaluar si una diferencia de trato es admisible o si, por el contrario, carece de justificación admisible ${ }^{110}$.

En síntesis, ni el texto de la Constitución, ni la doctrina, ni la jurisprudencia se refieren a la prohibición de discriminar como un derecho subordinado a algún otro derecho constitucional. Lejos de ello, la admisión de diferencias de tratamiento no deriva de una supuesta preferencia general de ciertos derechos o bienes jurídicos por sobre la prohibición de discriminar, sino del respeto de los criterios de razonabilidad, objetividad y, singularmente, el principio de proporcionalidad, es decir, si la diferencia de trato cuenta con una justificación admisible.

\section{JeRARQUía DE LA NO DISCRIMINACiÓN EN LA LEY 20.609}

Según se ha expresado más arriba, el inciso primero del artículo $2^{\circ}$ de la ley en comentario entiende que se produce una discriminación cuando se establece una distinción, exclusión o restricción que carece de justificación razonable y que afecta derechos fundamentales estatuidos en la Constitución o en los tratados ratificados y vigentes, "en particular cuando se funden" en alguno de los criterios sospechosos.

El inciso tercero del mismo artículo agrega la siguiente disposición: "Se considerarán razonables las distinciones, exclusiones o restricciones que, no obstante fundarse en alguno de los criterios mencionados en el inciso primero, se encuentren justificadas en el ejercicio legítimo de otro derecho fundamental, en especial los referidos en los números $4^{\circ}, 6^{\circ}, 11^{\circ}$, $12^{\circ}, 15^{\circ}, 16^{\circ}$ y $21^{\circ}$ del artículo 19 de la Constitución Política de la República, o en otra causa constitucionalmente legítima”.

La consideración conjunta de ambas disposiciones permite concluir que, pese a que se cumplan los tres requisitos para estar en presencia de una discriminación (diferencia de trato, falta de justificación razonable y afectación de derechos fundamentales) y aun cuando se funden en algún criterio sospechoso, en ciertos casos no existirá discriminación.

El primero de esos casos consiste en que la diferencia de trato se justifique en el ejercicio legítimo de otro derecho fundamental. Al respecto conviene advertir que, según la ley, la prohibición de discriminar no solo debe ceder frente a los derechos incluidos en los números del artículo 19 de la Constitución que ella misma menciona, porque dicha referencia es meramente ejemplar ${ }^{111}$. En realidad debe ceder frente a cualquier otro derecho funda-

109 La proporcionalidad es referida, por ejemplo, en las sentencias recaídas en las causas rol 1988-2011-CPT, de 24 de junio de 2011, considerandos sexagésimo séptimo y sexagésimo octavo, rol 1812 (1816-1817)-10CAA, de 18 de agosto de 2011, considerandos vigésimo noveno y trigésimo, y rol 1307-09-INA, de 20 de enero de 2011, considerando décimo cuarto. Ver Convenio Internacional para la Protección de Obtenciones Vegetales (UPOV-91), rol 1988 (2011), Artículo 7o del Auto Acordado sobre tramitación y fallo del recurso de protección de garantías constitucionales de la Corte Suprema, rol 1912 (1916-1817) (2011) y Artículos 22 y 25, No 2 de la Convención de Varsovia, rol 1307 (2011).

110 En este mismo sentido, Bulnes explica que desde sus primeras sentencias el Tribunal Constitucional solo admitía las diferencias de trato que se fundan en el criterio de la razonabilidad. "Solamente a partir del año 2007 -añade- nos encontramos con sentencias que se apartan de esta tesis y establecen para aceptar las diferencias que pueda imponer el legislador otras exigencias". Ver Bulnes (2009) especialmente pp. 20 a 22.

111 Esta afirmación es resultado de interpretar la expresión "en especial" en el sentido de "particularmente" o 
mental, sea que se contemple en la Constitución o en tratados internacionales ratificados y vigentes.

El segundo de los casos se produce cuando la diferencia de trato que lesiona derechos fundamentales, en particular si se basa en alguno de los criterios sospechosos, se funda en alguna causa constitucionalmente legítima. Siguiendo la doctrina constitucional, se podría pensar que con esta imprecisa expresión "alguna causa constitucionalmente legítima” se alude a bienes jurídicos constitucionales ${ }^{112}$. Ello se debe a que los derechos constitucionales, como lo es la prohibición de discriminar, solo pueden ser limitados por normas de jerarquía constitucional ${ }^{113}$, y singularmente por los derechos y los bienes jurídicos establecidos en ellas ${ }^{114}$.

Lo recién evidenciado permite concluir que en la ley el derecho a no ser discriminado aparece subordinado a cualquier otro derecho fundamental y a cualquier bien constitucional, desde que la colisión entre aquella y estos últimos es resuelta directamente por la ley de manera incondicionada a favor de tales derechos y de tales bienes. Esto se hace por la vía de sostener, en la propia ley, que desaparece la falta de razonabilidad en la distinción si la misma se funda en el ejercicio legítimo de algún derecho fundamental o de cualquier causa constitucionalmente legítima.

Es efectivo que durante el tercer trámite constitucional del proyecto de ley que dio lugar a la ley 20.609 la Cámara de Diputados rechazó el artículo $3^{\circ}$ propuesto por el Senado ${ }^{115}$. De este modo, se rechazó también el inciso tercero del mismo, que coincidía con el actualmente vigente, aunque intercalaba la palabra "siempre" entre las expresiones "Se considerarán” y "razonables". Pues bien, aunque el texto de consenso eliminó la palabra "siempre”, quedando la redacción como se aprecia en la ley aprobada, el cambio no parece suficiente.

En efecto, durante la tramitación parlamentaria del proyecto algunos entendieron que este cambio implicaba sustituir una presunción de Derecho en perjuicio de quien es víctima de discriminación por una presunción simplemente legal en su contra ${ }^{116}$. Incluso

\footnotetext{
"debiendo considerarse singularmente".

112 Para efectos de este trabajo se entiende por bien jurídico constitucional a aquel elemento incluido en una norma constitucional que, sin atribuir derechos subjetivos, establece un interés o valor que debe ser alcanzado en el mayor grado posible, dentro de las posibilidades jurídicas y fácticas.

113 De ahí que Alexy exprese que "Los derechos fundamentales, en tanto derechos de rango constitucional, pueden ser restringidos solo a través de, o sobre la base de, normas con rango constitucional”. Sobre estas categorías, Alexy precisa que "las restricciones de derechos fundamentales son siempre o bien normas de rango constitucional o normas de rango inferior al de la Constitución, a las que autorizan dictar normas constitucionales. Las restricciones de rango constitucional son directamente constitucionales; las restricciones de rango inferior a la Constitución, indirectamente constitucionales" (las cursivas son del texto citado). Alexy (2001) p. 277. 114 "Los derechos que ejerce cada individuo tienen como límite el respeto al ejercicio de los derechos de los demás miembros de la sociedad, como asimismo los bienes jurídicos que establece el orden constitucional en la perspectiva del bien común”, expresa Nogueira (1997) p. 282.

115 Biblioteca del Congreso Nacional, Historia de la ley 20.609, pp. 840 y 973.

116 Al respecto expresó el representante de Amnistía Internacional en la comisión mixta: "Este problema no se soluciona eliminando la expresión "siempre". En efecto, si se eliminara la expresión "siempre", se trataría de una presunción simplemente legal y de todas formas termina invirtiendo la carga de la prueba en perjuicio de las víctimas. La víctima de la discriminación queda en una situación sumamente desmejorada considerando que: i) además de probar la discriminación debería acreditar la falta de razonabilidad y las motivaciones del acto
} 
se sostuvo que la redacción aprobada en la comisión mixta permitía que los jueces jerarquizaran en cada caso el derecho a no ser discriminado con los demás derechos fundamentales ${ }^{117}$. Sin embargo, resulta igualmente posible sostener que dicho cambio fue irrelevante y que los derechos a la igualdad y a la no discriminación se subordinan a los demás derechos fundamentales y a cualquier otra causa constitucionalmente legítima, como también se afirmó en la tramitación parlamentaria ${ }^{118}$. Esta parece ser, por lo demás, la más directa y simple de las interpretaciones a partir del tenor literal de la disposición en comentario y resulta coherente con la inteligencia dada a la misma por el voto particular de los integrantes del Tribunal Constitucional ministros Vodanovic y Viera-Gallo al pronunciarse sobre esta iniciativa de ley ${ }^{119}$.

\section{EVALUACiÓN DE LA JERARQUía DE LA NO DISCRIMINACión EN LA LEY}

Los aportes del Derecho internacional y del Derecho constitucional permiten, según se ha visto, concluir dos cosas. En primer lugar, que no existe una preferencia abstracta e incondicionada a favor de otros derechos fundamentales, sean del ámbito interno o internacional, respecto de la prohibición de discriminar. En segundo lugar, y en consecuencia, que no es la tutela de aquellos derechos o bienes lo que suprime el carácter discriminatorio de una diferencia de trato, sino el cumplimiento de los criterios de razonabilidad, objetividad y de legitimidad o proporcionalidad, cuya satisfacción permite considerar que existe una justificación admisible para la diferencia de trato ${ }^{120}$.

De este modo, la ley en comentario incluye una solución para las colisiones que se puedan presentar entre la prohibición de discriminación y el ejercicio de otros derechos fundamentales o bienes jurídicos constitucionales que se divorcia totalmente de lo establecido por las diversas fuentes del Derecho internacional de los derechos humanos y del

discriminatorio y ii) en materia de discriminación es frecuente la asimetría entre las partes, ya que normalmente quien discrimina se encuentra en mejores condiciones para acreditar la razonabilidad de la discriminación”. Biblioteca del Congreso Nacional, Historia de la ley 20.609, p. 1003.

117 Esta fue la opinión de los senadores Hernán Larraín y Patricio Walker durante la discusión en sala. Ver Biblioteca del Congreso Nacional, Historia de la ley 20.609, pp. 1158 y 1159, y 1173, respectivamente.

118 En este sentido, sostuvo la diputada María Antonieta Saa en la discusión en sala del proyecto aprobado por la comisión mixta: "Así, el inciso tercero del artículo $2^{\circ}$-al respecto, quiero hacer reserva de constitucionalidad- establece una jerarquía entre los derechos y las libertades individuales. Hay algunos más importantes que otros, y el derecho a no ser discriminado queda al final de la lista. Eso no es constitucional". Biblioteca del Congreso Nacional, Historia de la ley 20.609, p. 1141. En esta posición parece posible incluir al senador Gómez, quien al comentar la oración "se considerarán siempre razonables" sostuvo: "Yo simplemente, para los casos de objeciones por considerarse injustificada una discriminación, habría planteado que se recurriera a los tribunales", con lo que da a entender que la ponderación habría sido realizada anticipadamente por el legislador. Ver Biblioteca del Congreso Nacional, Historia de la ley 20.609, p. 1178.

119 Precisamente fundados en esta inteligencia de la disposición, que afectaba en su esencia el derecho fundamental a la igualdad, los mencionados ministros sostuvieron la inconstitucionalidad del inciso tercero del artículo $2^{\circ}$ del proyecto de ley que dio lugar a la ley 20.609. Ver causa rol 2231-2012.

120 Parece necesario destacar que los criterios de objetividad, razonabilidad y proporcionalidad erigidos por las jurisprudencias internacional y constitucional no constituyen un tercer requisito del concepto de discriminación. Según se ha dicho, aquellos son criterios cuya concurrencia permite considerar que la diferencia de trato cuenta con una justificación admisible, es decir, tener por cumplido el segundo de los requisitos del concepto de discriminación. 
Derecho constitucional chileno. En efecto, se establece como regla la preferencia incondicionada de tales derechos y bienes constitucionales por sobre la prohibición de discriminar, mediante la validación legal de toda diferencia de trato que se funde en el ejercicio legítimo de tales derechos o en alguna causa constitucionalmente legítima ${ }^{121}$.

La consecuencia jurídica de esta relación de preferencia incondicionada en perjuicio del derecho a la no discriminación se evidencia en el ámbito judicial. En efecto, el juez deberá rechazar las acciones derivadas de la mencionada ley si el denunciado justifica su actuar discriminatorio alegando que ha ejercido cualquier derecho fundamental o que le ampara alguna causa constitucionalmente legítima. De este modo, una vez más la acción procesal establecida por la ley aparece debilitada respecto de otras opciones procesales ofrecidas por el ordenamiento jurídico nacional. En palabras de Zúñiga, esto contradice la doctrina y jurisprudencia comparada e internacional consolidada en materia de derechos humanos" respecto del modo en que deben ser resueltos los conflictos entre derechos fundamentales o principios jurídicos ${ }^{122}$.

\section{CONCLUSIONES}

1. Este trabajo se inició recordando que la no discriminación constituye un principio del Derecho internacional de los derechos humanos y un valor en el ordenamiento constitucional chileno que, por lo mismo, debe ser efectivamente tutelado por el ordenamiento jurídico. Desde tales coordenadas, las preguntas que han orientado la investigación han sido las siguientes: ¿es coherente la concepción de discriminación contenida en la ley 20.609 con la concepción de discriminación sostenida por el Derecho internacional de los derechos humanos y por el Derecho constitucional chileno? ¿Qué consecuencias acarrea la respuesta a la pregunta anterior en la utilidad que presenta la acción procesal establecida en la propia ley?

2. La respuesta a la primera pregunta deriva del contraste entre la concepción de discriminación contenida en la ley 20.609 y la que se expresa en las normas del Derecho internacional de los derechos humanos y el Derecho constitucional. Dicho contraste permite concluir que existe discrepancia entre la ley evaluada y los ámbitos normativos que le sirven de estándar en los tres aspectos que constituyen aquella concepción.

En efecto, y en cuanto al concepto, la ley entiende que existe discriminación cuando se produce una diferencia de trato que carece de justificación admisible y que, además, vulnera algún derecho fundamental. Por el contrario, desde el punto de vista de los Derechos internacional y constitucional una conducta puede ser discriminatoria aun cuando no se afecten otros derechos fundamentales. De este modo, en la ley se establece una exigencia adicional a la constitucional e internacional para calificar de discriminatoria una determinada conducta.

\footnotetext{
121 Aunque analizar este problema excede las pretensiones del presente trabajo, conviene al menos enunciar que la relación de preferencia incondicionada en perjuicio del derecho a no ser discriminado podría ser inconstitucional, desde que se subordina este último a todos los demás derechos fundamentales.

122 ZúNíiga (2012).
} 
En segundo lugar, y respecto de las propiedades que tienen la calidad de categorías sospechosas, la ley utiliza la indeterminada expresión "en particular" para enlazar tales propiedades con la configuración de una conducta discriminatoria. Esto genera un agudo problema interpretativo que priva a tales propiedades de la función que cumplen, en particular en el Derecho internacional, de alertar una discriminación cuando la diferencia de trato se funda en alguna de tales categorías.

Por último, y en cuanto a la solución de colisiones entre la no discriminación y otros derechos fundamentales o bienes jurídicos constitucionales, la ley establece una relación de precedencia incondicionada en perjuicio de la primera. Esta solución se opone directamente con el modo en que el Derecho internacional y el Derecho constitucional resuelven tales colisiones, pues en ellos se acude a los criterios de razonabilidad, objetividad y proporcionalidad.

3. La respuesta a la segunda pregunta se infiere de lo recién expresado.

$\mathrm{Al}$ incluir un tercer requisito en el concepto de discriminación, la ley 20.609 incrementa la exigencia probatoria de quien desee utilizar la acción procesal contemplada en la misma, respecto de, por ejemplo, la acción de protección. En efecto, en este último caso basta probar la diferencia de trato y que dicha diferencia ha carecido de justificación admisible. De este modo, la ley ha introducido una nueva acción en el ordenamiento jurídico chileno que, desde el punto de vista probatorio, es perjudicial para quien alega una discriminación respecto de otras acciones existentes con anterioridad.

Por otra parte, al referirse de manera tan imprecisa a la función de las categorías sospechosas, la ley 20.609 incrementa la exigencia argumental de quien desee utilizar la acción procesal contemplada en la misma, respecto de, por ejemplo, la acción de protección. En efecto, en este último caso basta probar que la diferencia de trato se ha fundado en alguna de las propiedades sospechosas para que tal distinción sea indiciariamente discriminatoria. Para tener esta misma ventaja argumental, quien utiliza la acción procesal contemplada en la ley deberá persuadir al juzgador para que elija una determinada interpretación de las expresiones "en particular", de las muchas que fundadamente se pueden ofrecer.

Por último, al resolver de manera anticipada las colisiones entre la no discriminación y cualquier otro derecho fundamental o algún bien jurídico constitucional, en perjuicio de la primera, la ley 20.609 prácticamente inutiliza la acción procesal que la misma contempla. En efecto, al demandado le bastará acreditar que ha obrado en ejercicio de cualquiera de esos derechos o bienes jurídicos para que el juez deba desechar aquella acción. En el ámbito constitucional, en cambio, el juzgador debe realizar un análisis de proporcionalidad para resolver la colisión. En consecuencia, quien acciona tiene siempre la posibilidad de argumentar por qué su posición debe prevalecer frente al derecho o bien jurídico alegado por la contraparte.

4. De conformidad con lo que se ha expuesto, la concepción de discriminación que contiene la ley 20.609 diverge profundamente de la concepción expresada en los Derechos internacional y constitucional, en perjuicio de quien desea alegar que ha sido víctima de una discriminación. Esta divergencia no es, según se ha mostrado, solo un problema teórico, sino que arrastra importantes consecuencias prácticas respecto de la acción procesal regulada en la misma ley, cuya utilidad es, según lo analizado, dudosa. 


\section{BIBLIOGRAFÍA CITADA}

\section{LiBros}

Alexy, Robert (2001): Teoría de los derechos fundamentales (trad. Ernesto Garzón Valdés, Madrid, Centro de Estudios Políticos y Constitucionales) 554 pp.

Bronfman Vargas, Alan, Martínez Estay, José Ignacio y Núñez Poblete, Manuel (2012): Constitución Política comentada (Santiago de Chile, Abeledo Perrot-LegalPublishing) $562 \mathrm{pp}$.

Cea Egaña, José Luis (2004): Derecho constitucional chileno (Santiago de Chile, Ediciones Universidad Católica de Chile, tomo II) 733 pp.

Clérico, Laura (2009): El examen de proporcionalidad en el Derecho constitucional (Buenos Aires, Eudeba) 408 pp.

Evans de la Cuadra, Enrique (2004): Los derechos constitucionales (Santiago de Chile, Jurídica de Chile, tomo II, tercera edición actualizada) 391 pp.

Fernández González, Miguel Ángel (2001): Principio constitucional de igualdad ante la ley (Santiago de Chile, ConoSur) 351 pp.

Mendonca, Daniel, y Guibourg, Ricardo A. (2004): La odisea constitucional. Constitución, teoría y método (Madrid, Marcial Pons) $222 \mathrm{pp}$.

Nogueira Alcalá, Humberto (2008): Derechos fundamentales y garantías constitucionales (Santiago de Chile, Librotecnia, tomo II) 748 pp.

Nogueira Alcalá, Humberto (1997): Dogmática constitucional (Talca, Editorial Universidad de Talca) 380 pp.

Oficina Regional para América Latina y el Caribe del Alto Comisionado de Naciones Unidas para los Derechos Humanos (2007): Derecho Internacional de los derechos humanos (Santiago de Chile, segunda edición) 1.064 pp.

Silva Bascuñán, Alejandro (1997): Tratado de Derecho constitucional (Santiago de Chile, Jurídica de Chile, tomo IV, segunda edición) 376 pp.

Silva Bascuñán (2006): Tratado de Derecho constitucional (Santiago de Chile, Jurídica de Chile, tomo XI) 313 pp.

Verdugo Marinkovic, Mario, Peffer Urquiaga, Emilio y Nogueira Alcalá, Humberto (2002): Derecho constitucional (Santiago de Chile, Editorial Jurídica de Chile, tomo I, segunda edición) 375 pp.

\section{CapÍtulos de libros}

Bernal Pulido, Carlos (2002): "El juicio de la igualdad en la jurisprudencia de la Corte Constitucional colombiana”, en: Vega Gómez, Juan y Corzo Sosa, Edgar (coord.) Instrumentos de tutela y justicia constitucional, Memoria del VII Congreso Iberoamericano de Derecho constitucional (México, Instituto de Investigaciones Jurídicas de la Universidad Nacional Autónoma de México) pp. 51-74. 
Bulnes Aldunate, Luz (2009): "La igualdad ante la ley y la evolución de la jurisprudencia del Tribunal Constitucional", en: Asociación Chilena de Derecho Constitucional, Temas actuales de Derecho constitucional (Santiago de Chile, Editorial Jurídica de Chile) pp. 17-26.

SABA, Roberto P. (2008): "Igualdad, clases y clasificaciones: ¿Qué es lo sospechoso de las categorías sospechosas?”, en Gargarella, Roberto, Teoría y crítica del Derecho constitucional, (Buenos Aires, Abeledo Perrot, tomo II) pp. 695-742.

SÁnChez GIL, Rubén (2010): "El principio de proporcionalidad en la jurisprudencia mexicana", en: Alexy, Robert, y otros, El principio de proporcionalidad en la interpretación jurídica (Santiago de Chile, Librotecnia) pp. 297-352.

\section{Artículos de ReVistas}

Clérico, Laura y Aldao, Martín (2011): "La igualdad como redistribución y como reconocimiento: derechos de los pueblos indígenas y Corte Interamericana de Derechos Humanos", Revista Estudios Constitucionales, año 9, No 1: pp. 157-198.

Cobreros Mendazona, Edorta (2007): “Discriminación por indiferenciación: estudio y propuesta”, Revista Española de Derecho Constitucional, $\mathrm{N}^{\circ}$ 81, septiembre-diciembre 2007: pp. 71-114.

Contreras V., Pablo, García P., Gonzalo, Jordán D., Tomás y Villanueva R., Álvaro (2010): "Informe en Derecho presentado ante el Tribunal Constitucional en el proceso de inconstitucionalidad del artículo 38 ter de la ley 18.933”, Revista Estudios Constitucionales, año 8, $\mathrm{N}^{\circ}$ 2: pp. 633-674.

Jiménez Campo, Javier (1983): "La igualdad jurídica como límite frente al legislador", Revista Española de Derecho Constitucional, año 3, N 9, septiembre-diciembre 1983: pp. 71-114.

Martin Cubas, Joaquín (1998): "El concepto de igualdad en una democracia avanzada: Un estudio de la jurisprudencia del Tribunal Constitucional”, Revista Española de Derecho Constitucional, año 18, № 53, mayo-agosto 1998: pp. 155-188.

Nogueira Alcalá, Humberto (2006): "El derecho a la igualdad ante la ley, la no discriminación y acciones positivas", Anuario da Facultade de Dereito da Universidade da Coru$\tilde{n} a, \mathrm{~N}^{\circ} 10$ : pp. 799-831.

Rubio Llorente, Francisco (1991): "La igualdad en la jurisprudencia del Tribunal Constitucional, Introducción”, Revista Española de Derecho Constitucional, No 31, enero-abril: pp. 9-38.

Sarmiento, Daniel (2003): "El principio de proporcionalidad y la defensa de la autonomía local”, Revista de Administración Pública, 162 (2003) septiembre-diciembre: pp. 145-171.

Zúniga AÑasco, Yanira (2010): "El principio de proporcionalidad como herramienta de racionalidad. Un análisis crítico de su aplicación en la jurisprudencia del Tribunal Constitucional chileno", Revista Ius et Praxis, 16 (2010) 2: pp. 249-272. 


\section{DOCUMENTOS EN FORMATO ELECTRÓNICO}

Biblioteca del Congreso Nacional, Historia de la ley 20.609. Establece medidas contra la discriminación. Disponible en: http://www.bcn.cl/histley/historias-de-la-ley-ordenadas-por-numero [fecha de consulta: 22 de noviembre de 2012].

Comanducci, Paolo (1998): “Igualdad liberal”. Disponible en: www.palermo.edu/derecho/publicaciones/pdfs/revista_juridica/n3N2-Octubre1998/032Juridica03.pdf [fecha de consulta: 7 de febrero de 2009].

Corral Talciani, Hernán (2012): "Ataque a joven homosexual: ¡es necesaria la ley antidiscriminación?”. Disponible en: http://www.diarioconstitucional.cl/mostrararticulo. php?id=134 [fecha de consulta: 29 de julio de 2012].

Corte Suprema (2005a): Oficio No 58 Informe proyecto de ley 11-2005, de 3 de mayo de 2005. Disponible en: http://camara.cl/pley/pdfpley.aspx?prmID=9563\&prmTIPO=OF ICIOPLEY [fecha de consulta: 31 de julio de 2012].

Corte Suprema (2005b): Oficio $N^{\circ} 168$, Informe proyecto de ley 48-2005, de 15 de noviembre de 2005. Disponible en http://camara.cl/pley/pdfpley.aspx?prmID=10419\&pr mTIPO=OFICIOPLEY [fecha de consulta: 31 de julio de 2012].

Corte Suprema (2007): Oficio No 27, Informe proyecto de ley 65-2006, de 23 de enero de 2007. Disponible en: http://camara.cl/pley/pdfpley.aspx?prmID $=12146 \&$ prmTIPO=O FICIOPLEY [fecha de consulta: 31 de julio de 2012].

Corte Suprema (2008): Oficio No 96, Informe proyecto de ley 17-2008, de 23 de junio de 2008. Disponible en: http://camara.cl/pley/pdfpley.aspx?prmID $=13478 \&$ prmTIPO=O FICIOPLEY [fecha de consulta: 31 de julio de 2012].

Corte Suprema (2011): Oficio N 126-2011, Informe proyecto de ley 31-2011, de 29 de julio de 2011. Disponible en: http://camara.cl/pley/pdfpley.aspx?prmID=16393\&prmT IPO=OFICIOPLEY [fecha de consulta: 31 de julio de 2012].

Figueroa G., Rodolfo (2000): "Igualdad y discriminación”. Disponible en: www.udp.cl/ derecho/derechoshumanos/publicaciones/10/figueroa.pdf [fecha de consulta: 22 de julio de 2008].

Llanquilef Durán, Pablo (2012): "Notas críticas a la política legislativa chilena: la ley de "Tolerancia cero al alcohol en la conducción" y especialmente la ley antidiscriminación”. Disponible en: http://www.iusnovum.com/wordpress/notas-criticas-a-la-politicalegislativa-chilena-la-ley-de-tolerancia-cero-al-alcohol-en-la-conduccion-y-especialmente-la-ley-antidiscriminacion/ [fecha de consulta: 10 de mayo de 2012].

Oficina Regional para América del Sur del Alto Comisionado de las Naciones Unidas para los Derechos Humanos (2011). Disponible en: http://acnudh.org/wp-content/ uploads/2012/04/OHCHR-Chile-Harmonization-Report-Bolet\%C3\%ADn-3.815-07. pdf [fecha de consulta: 25 de abril de 2012].

Palacios Zuloaga, Patricia (2006): "La no discriminación. Estudio de la jurisprudencia del Comité de Derechos Humanos sobre la cláusula autónoma de no discriminación”. Disponible en: www.upnfm.edu.hn/bibliod/images/stories/.../la-no-discriminacion.pdf [fecha de consulta: 28 de noviembre de 2012]. 
Tórtora, Hugo (2012): "Proyecto de ley antidiscriminación. Algunas ideas importantes". Disponible en: http://diarioconstitucional.cl/mostrararticulo.php?id=153 [fecha de consulta: 27 de abril de 2012].

ZúNíga Fajuri, Alejandra (2011): "Se prohíbe discriminar, salvo que... ¿Está justificada la letra chica del proyecto?”. Disponible en: http://diarioconstitucional.cl/mostrararticulo. php?id=87\&idautor=76 [fecha de consulta: 30 de abril de 2012].

\section{NORMAS CiTADAS}

Declaración Universal de Derechos Humanos. Disponible en: http://www.un.org/es/documents/udhr/index.shtml [fecha de consulta: 28 de septiembre de 2007].

Pacto. Disponible en: http://www.unhchr.ch/spanish/html/menu3/b/a_ccpr_sp.htm [fecha de consulta: 28 de septiembre de 2007].

Convención Internacional sobre la eliminación de todas las formas de discriminación racial. Disponible en: http://www2.ohchr.org/spanish/law/cerd.htm. [fecha de consulta: 31 de julio de 2012].

Convención sobre la eliminación de todas las formas de discriminación contra la mujer. Disponible en: http://www.un.org/womenwatch/daw/cedaw/text/sconvention.htm [fecha de consulta: 31 de julio de 2012].

Convención de los derechos del niño. Disponible en: http://www2.ohchr.org/spanish/law/ crc.htm [fecha de consulta: 31 de julio de 2012].

Convención sobre los derechos de las personas con discapacidad. Disponible en: www. un.org/esa/socdev/enable/documents/tccconvs.pdf ]fecha de consulta: 31 de julio de 2012].

Declaración Americana de los derechos y deberes del hombre. Disponible en: http://www. cidh.org/basicos/Basicos1.htm [fecha de consulta: 25 de abril de 2012].

Convención Americana. Disponible en: http://www.oas.org/juridico/spanish/ Tratados/b-32.html [fecha de consulta: 28 de septiembre de 2007].

Constitución Política de la República de Chile, cuyo texto refundido, coordinado y sistematizado fue fijado por el decreto 100, de 2005, del Ministerio Secretaría General de la Presidencia. Disponible en: http://www.leychile.cl/Navegar?idNorma=242302\&idVersi on=2012-03-06 [fecha de consulta: 31 de julio de 2012]. Diario oficial, 22 de septiembre de 2005 .

Código del Trabajo, cuyo texto refundido, coordinado y sistematizado fue fijado por el decreto con fuerza de ley 1, de 2002, del Ministerio del Trabajo y Previsión Social. Disponible en: http://www.leychile.cl/Navegar?idNorma=207436\&idParte=0 [fecha de consulta: 31 de julio de 2012]. Diario Oficial, 16 de enero de 2003.

Ley 20.609, que establece medidas en contra de la discriminación. Disponible en: http:// www.leychile.cl/Navegar?idNorma=1042092 (fecha de consulta: 3 de agosto de 2012].

Ley 19.253, establece normas sobre protección, fomento y desarrollo de los indígenas, y crea la Corporación Nacional de Desarrollo Indígena. Disponible en http://www.leychile.cl/N?i=30620\&f=2008-05-09\&p= [fecha de consulta: 31 de julio de 2012]: . Diario Oficial, 5 de octubre de 1993. 
Ley $\mathrm{N}^{\circ} 18.834$, sobre Estatuto administrativo, cuyo texto refundido, coordinado y sistematizado fue fijado por el decreto con fuerza de ley 29, de 2004, del Ministerio de Hacienda. Disponible en: http://www.leychile.cl/N?i=236392\&f=2012-07-24\&p= [fecha de consulta: 31 de julio de 2012]. Diario Oficial, 16 de marzo de 2005.

\section{JURISPRUDENCIA CITADA}

(2000): Comité de Derechos Humanos de Naciones Unidas (Observación general $\mathrm{N}^{\circ}$ 28) Naciones Unidas, Instrumentos internacionales de derechos humanos. Volumen I. Recopilación de las Observaciones Generales y Recomendaciones Generales adoptadas por órganos creados en virtud de tratados de derechos humanos. Disponible en: http:// www2.ohchr.org/english/bodies/icm-mc/docs/8th/HRI.GEN.1.Rev9_sp.doc [fecha de consulta: 25 de abril de 2012].

Järvinen c. Finlandia (1990): Comité de Derechos Humanos de Naciones Unidas, 25 de julio de 1990 (Comunicación N²95/1988) Naciones Unidas, Selección de Decisiones del Comité de Derechos Humanos adoptadas con arreglo al Protocolo Facultativo, volumen 3, Nueva York y Ginebra, 2002. Disponible en: www.ohchr.org/Documents/ Publications/SDecisionsVol3sp.pdf [fecha de consulta: 6 de julio de 2012].

(1990): Comité de Derechos Económicos, Sociales y Culturales de Naciones Unidas (Observación general $\mathrm{N}^{\circ}$ 3) Naciones Unidas, Instrumentos internacionales de derechos humanos. Volumen I. Recopilación de las Observaciones Generales y Recomendaciones Generales adoptadas por órganos creados en virtud de tratados de derechos humanos. Disponible en: http://www2.ohchr.org/english/bodies/icm-mc/docs/8th/HRI. GEN.1.Rev9_sp.doc [fecha de consulta: 25 de abril de 2012].

(1989): Comité de Derechos Humanos de Naciones Unidas (Observación general $\mathrm{N}^{\circ}$ 18) Naciones Unidas, Instrumentos internacionales de derechos humanos. Volumen I. Recopilación de las Observaciones Generales y Recomendaciones Generales adoptadas por órganos creados en virtud de tratados de derechos humanos. Disponible en: http:// www2.ohchr.org/english/bodies/icm-mc/docs/8th/HRI.GEN.1.Rev9_sp.doc [fecha de consulta: 25 de abril de 2012].

Aumeeruddy-Cziffra c. Mauricio (1981): Comité de Derechos Humanos de Naciones Unidas, 9 de abril de 1981 (Comunicación Nº 35/1978) Naciones Unidas, Selección de Decisiones del Comité de Derechos Humanos adoptadas con arreglo al Protocolo Facultativo, $2^{\circ}$ a $16^{\circ}$ período de sesiones, Nueva York, 1988. Disponible en: http://www.cdh.uchile.cl/media/ publicaciones/pdf/15/222.pdf [fecha de consulta: 28 de noviembre de 2012].

Gueye y otros v. Francia (1989): Comité de Derechos Humanos de Naciones Unidas, 25 de julio de 1990 (Comunicación No 295/1988) Naciones Unidas, Selección de Decisiones del Comité de Derechos Humanos adoptadas con arreglo al Protocolo Facultativo, volumen 3, Nueva York y Ginebra, 2002. Disponible en: www.ohchr.org/Documents/Publications/SDecisionsVol3sp.pdf [fecha de consulta: 6 de julio de 2012].

Atala Riffo y niñas vs. Chile (2012): Corte Interamericana de Derechos Humanos, 24 de febrero de 2012 (fondo, reparaciones y costas). Disponible en: http://www.corteidh.or.cr/ docs/casos/articulos/seriec_239_esp.doc [fecha de consulta: 15 de junio de 2012]. 
Comunidad indígena Xákmok Kasek vs. Paraguay (2010): Corte Interamericana de Derechos Humanos, 24 de agosto de 2010 (Fondo, reparaciones y costas). Disponible en: http:// www.corteidh.or.cr/docs/casos/articulos/seriec_214_esp.doc [fecha de consulta: 27 de junion de 2012].

Niñas Yean y Bosico vs. República Dominicana (2005): Corte Interamericana de Derechos Humanos, 8 de septiembre de 2005 (sentencia). Disponible en: http://www.corteidh. or.cr/docs/casos/articulos/seriec_130_esp.doc [fecha de consulta: 27 de junio de 2012].

Solicitada por los Estados Unidos Mexicanos (2003): Corte Interamericana de Derechos Humanos, 17 de septiembre de 2003 (Opinión Consultiva OC 18/03) disponible en: http://www.corteidh.or.cr/docs/opiniones/seriea_18_esp.doc [fecha de consulta: 12 de junio de 2012].

Solicitada por Costa Rica (1984): Corte Interamericana de Derechos Humanos, 19 de enero de 1984 (Opinión Consultiva OC 4/84) disponible en: http://www.corteidh.or.cr/ docs/opiniones/seriea_04_esp.doc [fecha de consulta: 12 de junio de 2012].

Control de constitucionalidad respecto del proyecto de ley que establece medidas contra la discriminación (2012): Tribunal Constitucional de Chile, 28 de junio de 2012, rol 2231 (control preventivo de constitucionalidad). Disponible en: http://www.tribunalconstitucional.cl/wp/ver.php?id=2457 [fecha de consulta: 29 de noviembre de 2012].

Control de constitucionalidad del proyecto de ley que modifica la ley $\mathrm{N}^{\circ} 18.216$, que establece medidas alternativas a las penas privativas o restrictivas de libertad. (Boletín No 5838-07) (2012): Tribunal Constitucional de Chile, 5 de junio de 2012, rol 2230 (control preventivo de constitucionalidad). Disponible en: http://www.tribunalconstitucional.cl/wp/ver.php?id=2423 [fecha de consulta: 29 de junio de 2012].

Control de constitucionalidad del proyecto de ley sobre inscripción automática, Servicio Electoral y sistema de votaciones. (Boletín No 7338-07) (2012): Tribunal Constitucional de Chile, 19 de enero de 2012, rol 2152 (control preventivo de constitucionalidad). Disponible en: http://www.tribunalconstitucional.cl/wp/ver.php?id=2305 [fecha de consulta: 28 de marzo de 2012].

Requerimiento de inaplicabilidad por inconstitucionalidad presentado por Inversiones Rotondo Limitada respecto del inciso segundo del artículo 768 del Código de Procedimiento Civil, en los autos Rol No 8583-2009 sobre reclamo de ilegalidad interpuesto ante la Corte de Apelaciones de Santiago en contra de Municipalidad de Las Condes (2011): Tribunal Constitucional de Chile, 25 de agosto de 2011, rol 1873 (acción de inaplicabilidad). Disponible en: http://www.tribunalconstitucional.cl/wp/ver. php?id=2133 [fecha de consulta: 29 de marzo de 2012].

Requerimiento de inconstitucionalidad presentado por Isapre Cruz Blanca S.A. respecto del artículo $7^{\circ}$ del Auto Acordado sobre tramitación y fallo del recurso de protección de garantías constitucionales de la Corte Suprema, de 27 de junio de 1992, en los autos Rol No 3000-2010 sobre recurso de protección interpuesto ante la Corte de Apelaciones de Santiago (Secretaría Criminal) (1811): Tribunal Constitucional de Chile, 18 de agosto de 2011, rol 1812 (1816-1817) (requerimiento de inconstitucionalidad de auto acordado). Disponible en: http://www.tribunalconstitucional.cl/wp/ver.php?id=2123 [fecha de consulta: 28 de marzo de 2012]. 
Requerimiento de inaplicabilidad por inconstitucionalidad presentado por la Universidad Alberto Hurtado respecto del artículo 8, inciso primero, de la Ley No 17.322, que establece normas sobre Cobranza Judicial de imposiciones, aportes y multas de las Instituciones de Previsión (2011): Tribunal Constitucional de Chile, 9 de agosto de 2011, rol 1876 (acción de inaplicabilidad). Disponible en: http://www.tribunalconstitucional.cl/ wp/ver.php?id=2101 [fechad e consulta: 29 de marzo de 2012].

Requerimiento de inaplicabilidad por inconstitucionalidad presentado por Juan Pablo Parada Ruiz respecto de los artículos 38, inciso quinto de la Ley $\mathrm{N}^{\circ} 18.933$, en la parte que alude al factor etario; $2^{\circ}$ de la Ley $N^{\circ} 20.015$, y 22 de la Ley sobre Efecto Retroactivo de las Leyes, en relación a los autos Rol No 1825-2011, sobre recurso de protección deducido ante la Corte de Apelaciones de Santiago (Secretaría Criminal) en contra de la Isapre Cruz Blanca S.A. (2011): Tribunal Constitucional de Chile, 26 de julio de 2011, rol 1985 )acción de inaplicabilidad). Disponible en: http://www.tribunalconstitucional. cl/wp/ver.php?id=2073 [fecha de consulta: 28 de marzo de 2012].

Requerimiento presentado por 17 senadores respecto de la inconstitucionalidad del Convenio Internacional para la Protección de Obtenciones Vegetales (UPOV-91). Boletín No 6426-10 (2011): Tribunal Constitucional de Chile, 24 de junio de 2011, rol 1988 (requerimiento de inconstitucionalidad). Disponible en: http://www.tribunalconstitucional.cl/wp/ver.php?id=1987 [fecha de consulta: 28 de marzo de 2008].

Acción de inaplicabilidad por inconstitucionalidad de Pauline Jeanneret Elsner, respecto de los artículos 22 y 25, No 2 de la Convención de Varsovia (2011): Tribunal Constitucional de Chile, 20 de enero de 2011, rol 1307 (acción de inaplicabilidad). Disponible en: http:/www.tribunalconstitucional.cl/wp/ver.php?id=1741 [fecha de consulta: 30 de marzo de 2012].

Requerimiento de inaplicabilidad por inconstitucionalidad de Julio Miranda Lillo, respecto del artículo 35 de la Ley 18.962 y Decreto Ley No 479 de 1974, en recurso de Protección No 2 - 2010 de la Corte de Apelaciones de Valparaíso (2011): Tribunal Constitucional de Chile, 20 de enero de 2011, rol 1615 (acción de inaplicabilidad). Disponible en: http:/www.tribunalconstitucional.cl/wp/ver.php?id=1745 [fecha de consulta: 30 de marzo de 2012].

Proceso iniciado de oficio para decidir sobre la constitucionalidad del artículo 38 ter de la Ley de Isapres y cuya sentencia se publicó en el Diario Oficial el 9 de agosto de 2010 (2010): Tribunal Constitucional de Chile, 6 de agosto de 2010, rol 1710 [inconstitucionalidad de oficio). Disponible en: http://www.tribunalconstitucional.cl/wp/ver. php?id=1479 [fecha de consulta: 15 de junio de 2012].

Requerimiento de inaplicabilidad por inconstitucionalidad de Dagoberto Jara Garrido, respecto del artículo único de la Ley No 20.028,en rol No 3383 - 2008 de la Corte de Apelaciones de Santiago (2010): Tribunal Constitucional de Chile, 5 de agosto de 2010, rol 1452 (acción de inaplicabilidad). Disponible en: http://www.tribunalconstitucional. cl/wp/ver.php?id=1486 [fecha de consulta: 28 de junio de 2012].

Requerimiento de inconstitucionalidad del Presidente del Colegio de Abogados de Chile A.G., señor Enrique Barros Bourie, en representación de dicha entidad respecto del texto íntegro del artículo 595 del Código Orgánico de Tribunales. En subsidio de lo 
anterior, solicita se declare la inconstitucionalidad del inciso primero del mismo artículo $y$, en subsidio de esto último, se declare inconstitucional la expresión "gratuitamente", contenida en la misma norma legal (2009): Tribunal Constitucional de Chile, 29 de julio de 2009, rol 1254 (acción de inconstitucionalidad). Disponible en: http://www. tribunalconstitucional.cl/wp/ver.php?id=1197 [fecha de consulta: 6 de abril de 2012].

Requerimiento de inaplicabilidad por inconstitucionalidad de Sociedad Constructora SIGMA Limitada respecto del artículo 1891 del Código Civil en la causa Rol No5817-2008 del Vigésimo Cuarto Juzgado Civil de Santiago, caratulada "Sociedad Constructora Sigma Limitada con Banco de Chile” (2009): Tribunal Constitucional de Chile, 28 de mayo de 2009, rol 1204 (acción de inapllicabilidad). Disponible en: http://www.tribunalconstitucional.cl/wp/ver.php?id=1152 [fecha de consulta: 6 de abril de 2012].

Requerimiento de inaplicabilidad de José Tomás Rojas Rivera respecto del artículo 104 de la Ley General de Bancos, en causa rol 02-2007, seguida en el Primer Juzgado de Letras de Curicó, caratulada "CORPBANCA con ROJAS RIVERA, JOSÉ TOMÁS (2009): Tribunal Constitucional de Chile, 31 de enero de 2009, rol 1217 (acción de inaplicabilidad). Disponible en: http://www.tribunalconstitucional.cl/wp/ver.php?id=1105 [fecha de consulta: 6 de abril de 2012].

Control de constitucionalidad del proyecto de ley, aprobado por el Congreso Nacional, que fortalece y perfecciona la jurisdicción tributaria (Boletín $\left.N^{\circ} 3139-05\right)$ (2008): Tribunal Constitucional de Chile, 30 de diciembre de 2008, rol 1243 (control preventivo de constitucionalidad). Disponible en: http://www.tribunalconstitucional.cl/wp/ver. php?id=1076 [fecha de consulta: 30 de junio de 2012].

Requerimiento de inaplicabilidad de Waldo del Villar Mascardi respecto del artículo 61 de la Ley No 20.000, sobre tráfico ilícito de estupefacientes y sustancias sicotrópicas, en causa Rol No 76-2008 de la Corte de Apelaciones de Valparaíso (2008): Tribunal Constitucional de Chile, 18 de noviembre de 2008, rol 1133 (acción de inaplicabilidad). Disponible en: http://www.tribunalconstitucional.cl/wp/ver.php?id=1045 [fecha de consulta: 8 de abril de 2012].

Control de constitucionalidad del proyecto de acuerdo aprobatorio relativo al Convenio No 169 sobre pueblos indígenas, adoptado por la Organización Internacional del Trabajo, de 27 de junio de 1989 (Boletín No 233-10) (2008): Tribunal Constitucional de Chile, 3 de abril de 2008, rol 1050 (control preventivo de constitucionalidad). Disponible en: http://www.tribunalconstitucional.cl/wp/ver.php?id=904 [fecha de consulta: 29 de junio de 2012].

Requerimiento de inaplicabilidad deducido por Sociedad Ocean Front S.A.,respecto del artículo 107 de la Ley General de Bancos, en causa rol N 1144-2004, del 25 Juzgado Civil de Santiago (2008): Tribunal Constitucional de Chile, 31 de enero de 2008, rol 811 (acción de inaplicabilidad). Disponible en: http://www.tribunalconstitucional.cl/ wp/ver.php?id=849 [fecha de consulta: 11 de abril de 2012].

Requerimiento de inaplicabilidad presentado por Aarón David Vásquez Muñoz, respecto del artículo 387, inciso segundo, del Código Procesal Penal, en causa RUC N ${ }^{\circ}$ 0600764824-1, del $8^{\circ}$ Juzgado de Garantía de Santiago (2008): Tribunal Constitucional de Chile, 30 de enero de 2008, rol 986 (acción de inaplicabilidad). Disponible en: 
http://www.tribunalconstitucional.cl/wp/ver.php?id=730 [fecha de consulta: 11 de abril de 2012].

Requerimiento de inaplicabilidad presentado por Libertino Rivas Poblete, respecto de la letra d) del artículo 17, y del artículo 19 de la Ley $\mathrm{N}^{\circ}$ 18.216, que "Establece medidas que indica como alternativas a las penas privativas o restrictivas de libertad y deroga disposiciones que señala”, en la causa RIT N $\mathrm{N}^{\circ} 778-2006$, que se sigue ante el Juez de Garantía de Melipilla (2007): Tribunal Constitucional de Chile, 4 de octubre de 2007, rol 807 (acción de inaplicabilidad). Disponible en: http://www.tribunalconstitucional. cl/wp/ver.php?id=11 [fecha de consulta: 2 de mayo de 2012].

Control de constitucionalidad respecto del proyecto de ley orgánica constitucional sobre votaciones populares y escrutinios (1988): Tribunal Constitucional de Chile, 5 de abril de 1988, rol 53 (control preventivo de constitucionalidad). Disponible en: http://www. tribunalconstitucional.cl/wp/ver.php?id=556 [fecha de consulta: 30 de junio de 2012].

Manuel Moreno Rodríguez c. la Gobernación del Cesar (Secretaría de Deporte y Recreación) (2010): Corte Constitucional de Colombia, 11 de mayo de 2010, sentencia T-340/10 (acción de tutela). Disponible en: http://www.corteconstitucional.gov.co/ relatoria/2010/T-340-10.htm [fecha de consulta: 26 de noviembre de 2012].

Henry Páez Guzmán c. Corte Constitucional y Sala Administrativa del Consejo Superior de la Judicatura (2008): Corte Constitucional de Colombia, 15 de diciembre de 2008, sentencia T-1258/08 (acción de tutela). Disponible en: http://www.corteconstitucional.gov. co/relatoria/2008/T-1258-08.htm [fecha de consulta: 14 de junion de 2012].

Karumatsu v. United States (1944): Corte Suprema de Estados Unidos, 18 de diciembre de 1944 (323 U.S.). Disponible en: http://www.law.cornell.edu/supct/html/historics/ USSC_CR_0323_0214_ZO.html [fecha de consulta: 28 de noviembre de 2012]. 